(A) Check for updates

Cite this: Food Funct., 2020, 11, 3781

\title{
Effects of fasting intervention regulating anthropometric and metabolic parameters in subjects with overweight or obesity: a systematic review and meta-analysis $\uparrow$
}

\author{
Shoumeng Yan, ${ }^{a}$ Changcong Wang, ${ }^{a}$ Hantong Zhao, ${ }^{a}$ Yingan Pan, ${ }^{a}$ Han Wang, ${ }^{a}$ \\ Yinpei Guo, ${ }^{a}$ Nan Yao, ${ }^{a}$ Bo Li*a and Weiwei Cui ${ }^{*}{ }^{* b}$
}

\begin{abstract}
Background: Previous studies have shown that fasting produces a potential effect in the prevention and treatment of many diseases. However, the role of fasting in people with overweight or obesity remains controversial. The aim of this study was to assess the intervention of fasting in the regulation of anthropometric and metabolic parameters of subjects with overweight or obesity. Methods: The PubMed, Cochrane library, Web of science and EMBASE databases were searched from the inception dates to October 2019, identifying published literature evaluating the effect of fasting intervention on the people with overweight or obesity. Results: Twenty-five studies with 1358 participants with overweight or obesity were included in the meta-analysis. Fasting was associated with the significant reduction of body weight, body mass index (BMI), fat free mass (FEM), fat mass (FM), waist circumference (WC), low density lipoprotein cholesterol (LDL-C), triglycerides (TG), systolic blood pressure (SBP) and diastolic blood pressure (DBP). However, there was no significant difference in the variations in the total cholesterol (TC), high density lipoprotein cholesterol (HDL-C), blood glucose and insulin concentrations. Conclusion: Our meta-analysis found that fasting was associated with a significant effect on the regulation of anthropometric (body weight, BMI, FEM, FM and WC) and metabolic parameters (LDL-C, TG, SBP and DBP) in people with overweight or obesity. Considering some limitations found in this study, additional data from

large clinical trials are needed.
\end{abstract}

Received 2nd February 2020

Accepted 16th April 2020

DOI: $10.1039 /$ dOfo00287a

rsc.li/food-function

\section{Introduction}

Obesity is a pathological state in which excess abdominal weight is accumulated due to the imbalance between energy intake and consumption. ${ }^{1}$ The prevalence of obesity has doubled in more than 70 countries in the past 30 years and has constantly increased in most other countries. ${ }^{2}$ As excess weight gain increases the risk of cardiovascular disease, diabetes, cancer and other diseases; the increasing prevalence of obesity is a worldwide health problem and causes a large financial burden in all countries. ${ }^{3,4}$ By 2030 , a $5 \%$ decrease in body mass index (BMI) parameter is expected to lead to a

\footnotetext{
${ }^{a}$ Department of Epidemiology and Biostatistics, School of Public Health, Jilin University, Changchun, 130021, P. R. China.E-mail: li_bo@jlu.edu.cn; Tel: +8643185619451

${ }^{b}$ Department of Nutrition and Food Hygiene, School of Public Health, Jilin University, Changchun, 130021, P. R. China. E-mail: cuiweiwei@jlu.edu.cn; Tel: +8643185619455

$\dagger$ Electronic supplementary information (ESI) available. See DOI: 10.1039/ dofo00287a
}

reduction of $€ 495$ million in obesity related direct health care expenses over 20 years. ${ }^{5}$

Fasting is regarded as ingesting no or minimal energy for a period of time, which including periodic fasting $(\mathrm{PF})$, intermittent fasting (IF), very low calorie diet (VLCD) and other fasting. ${ }^{6,7}$ Among them, PF consists of fasting only 1 or 2 days per week with consuming food ad libitum on 5 to 6 days per week and VLCD is regarded as an energy intake of $800 \mathrm{kcal}$ or less per day. ${ }^{7-9}$ IF includes limiting or no food consumption on 1-3 day per week and eating freely on the no restriction days, which comprises complete alternate-day fasting (CADF), alternate day modified fasting (ADMF), timerestricted feeding (TRF) and others. ${ }^{10,11}$ The main difference between CADF and ADMF is the energy intake on fasting day (CADF: zero calorie intake; ADMF: $20-25 \%$ of energy needs). ${ }^{11,12}$ Specially, TRF is an eating pattern in which daily food consumption is limited to 8 hours or less. ${ }^{13}$ Previous studies have indicated that fasting produces a potential effect in the prevention and treatment of many diseases. Several studies have found that fasting was profitable for symptoms and inflammatory parameters in patients with 
rheumatic diseases. ${ }^{14,15}$ Meanwhile, the risk of hypertension, cardiovascular and metabolic disease was reduced through fasting intervention. ${ }^{7}$ In addition, fasting may protect from cancer via reducing the harm to cells and DNA, and increasing the death of precancerous cells. ${ }^{16}$ Simultaneously, fasting could also debase the capacity of cancer cells to adapt and survive, thereby improving the effects of cancer therapies. ${ }^{17}$

Some studies have reported that IF and VLCD may improve the body composition, reduce cardiovascular risk factors, and positively affect glucose control in people with overweight or obesity. ${ }^{18,19}$ However, recent research has also shown that the advantages of IF for weight loss, weight management, or cardio-protection in subjects with overweight or obesity were not obvious. ${ }^{20}$ The role of fasting in people with overweight or obesity remains controversial. Therefore, a meta-analysis of all related randomized control trials (RCTs) was conducted focusing on the intervention of fasting in the regulation of anthropometric and metabolic parameters of people with overweight or obesity.

\section{Materials and methods}

\subsection{Sources and methods of data retrieval}

We searched the PubMed, Cochrane library, Web of science and EMBASE databases from the inception dates to October 2019, using the keywords fasting, very low calorie diet, intermittent fasting, alternate day fasting, periodic fasting, modified fasting regimen, time-restricted feeding, overweight, obesity and obese to identify published literature evaluating the effect of fasting intervention on regulating anthropometric and metabolic parameters in people with overweight or obesity. The literature search was limited to English language and human subjects. The detailed search strategy is shown in Table S1. $\dagger$

\subsection{Inclusion criteria}

The inclusion criteria were (1) RCTs comparing fasting intervention and a normal diet or energy restriction group; (2) overweight or obesity was defined based on a local criterion; (3) the outcomes were quantitative data that could be extracted or

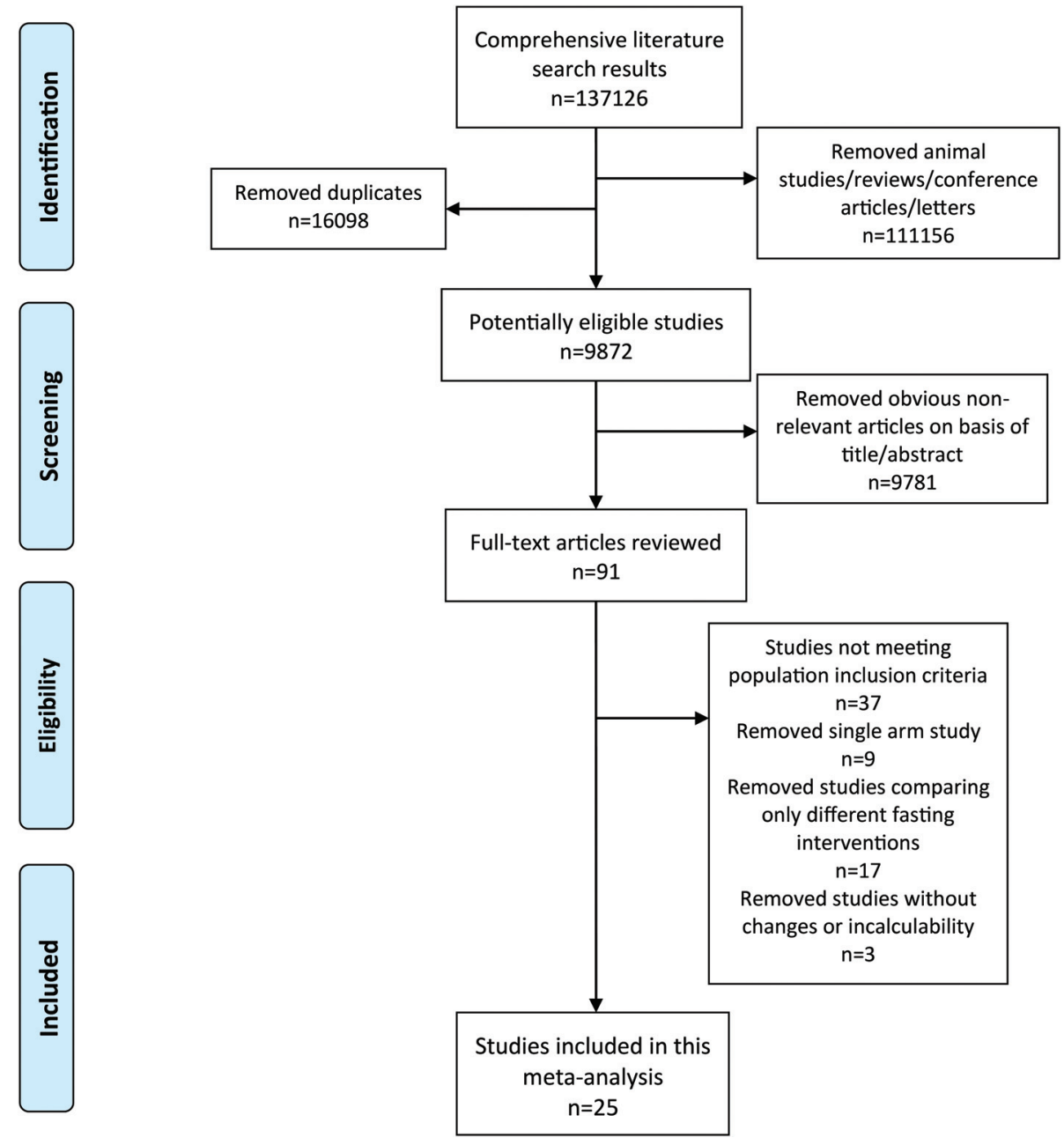

Fig. 1 Flow diagram of the literature search and selection. 


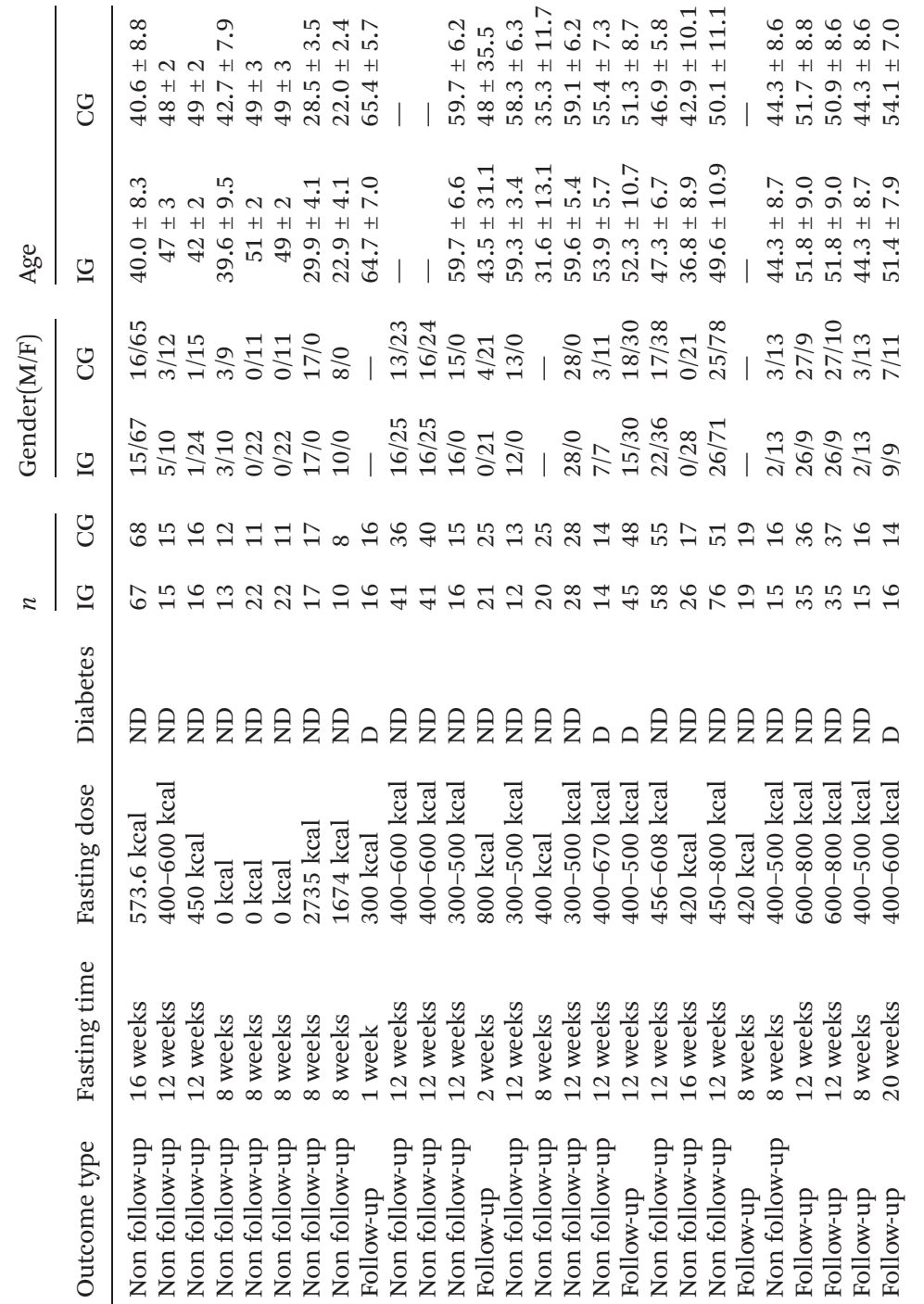

हE $\bar{\Sigma} \bar{\Sigma} \bar{\Sigma} \bar{\Sigma} \bar{\Sigma} \bar{\Sigma} \bar{\Sigma} \bar{\Sigma} \bar{\Sigma} \bar{\Sigma} \bar{\Sigma} \bar{\Sigma}$

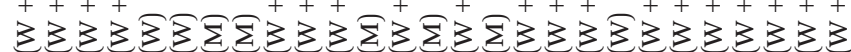

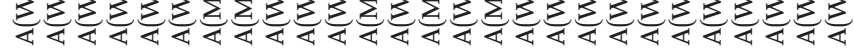

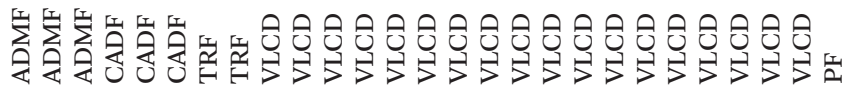

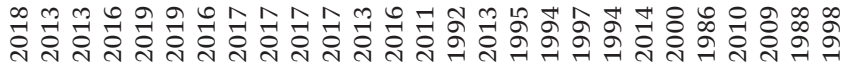

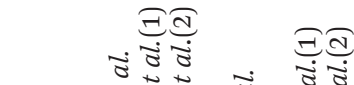

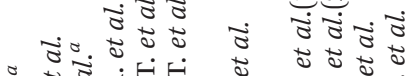

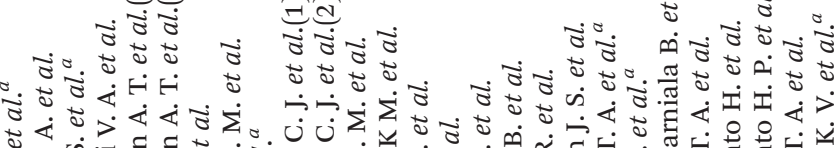
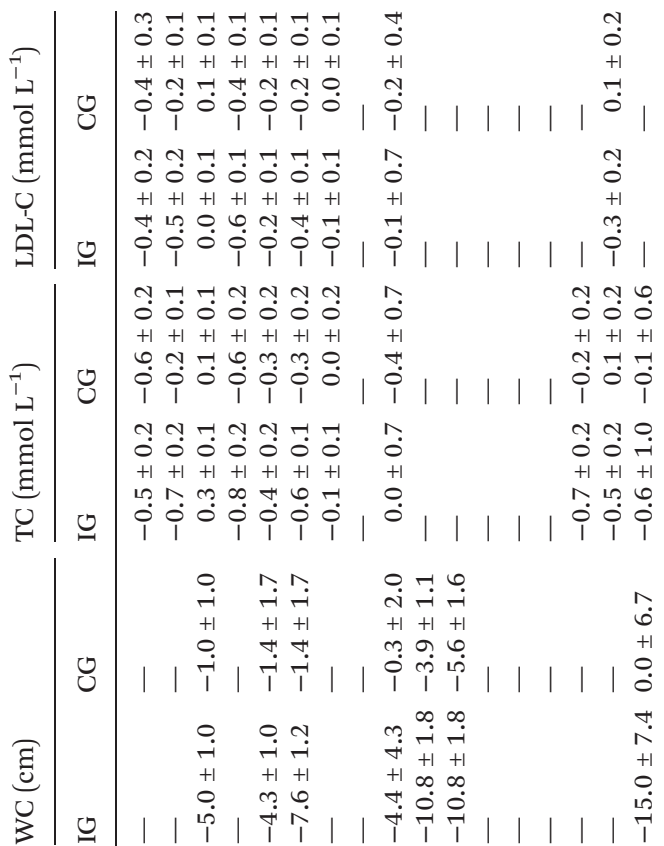

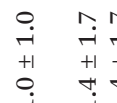

ర

焉

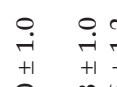

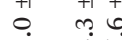

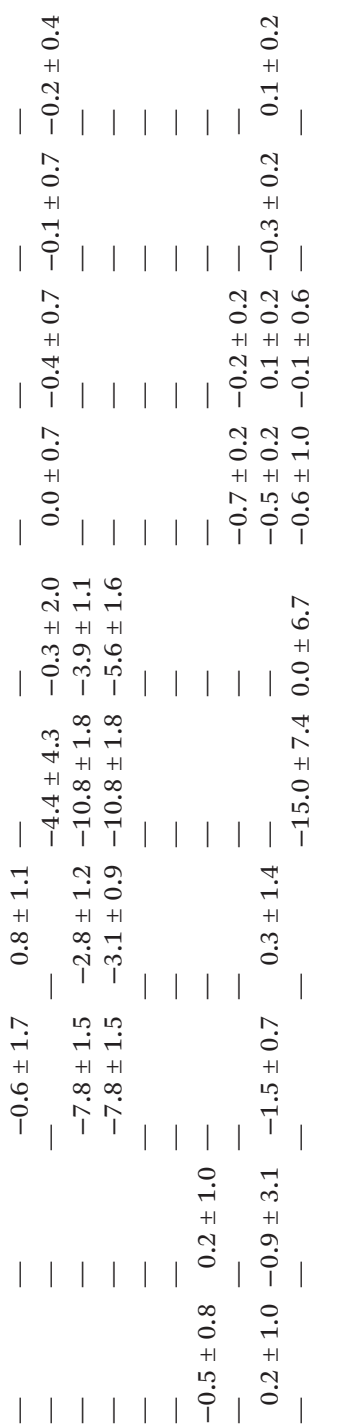

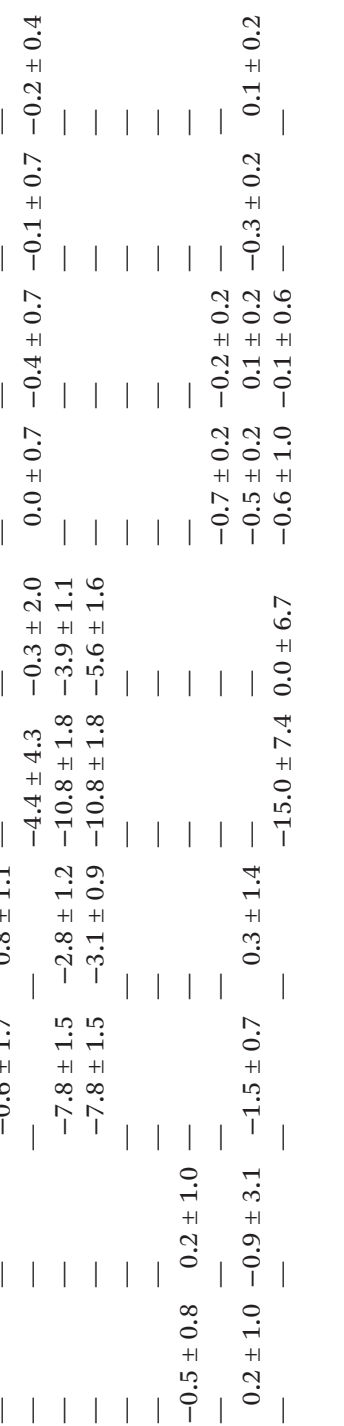

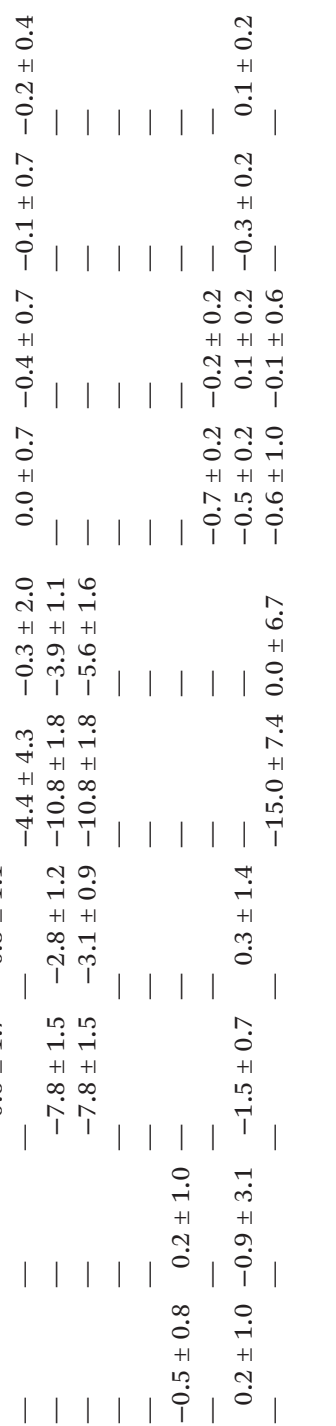

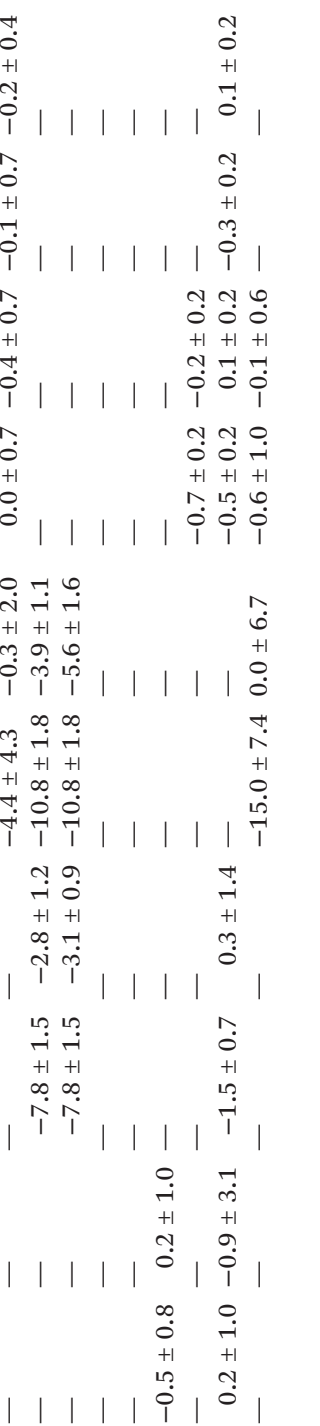

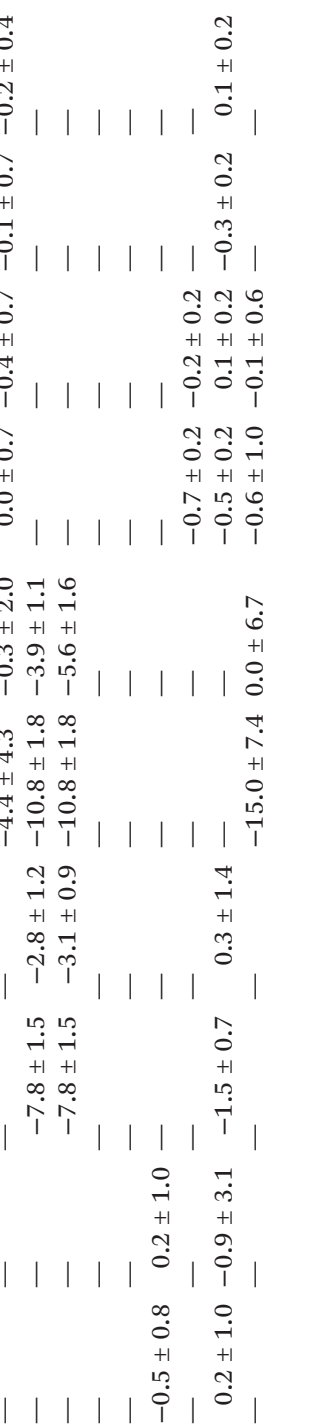

|1 | 1 | | | |

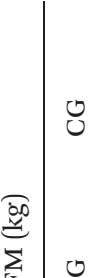

i०

政

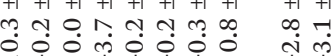

$\begin{array}{llll}1 & 1 & 1 & 1\end{array}$

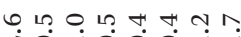

i.

से

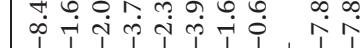

2

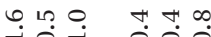

-i்

ช.

$\sum_{\substack{x=1 \\ i}}^{\infty}$

$\rightarrow$ i⿱⺈

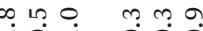

20

サ.

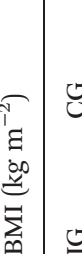

$\rightarrow \quad 0 \%$

$\begin{array}{lll}+1 & +1 & +1 \\ +1 & 0\end{array}$

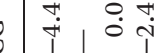

1

1

Tें

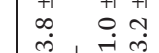

פ

में

mito -100

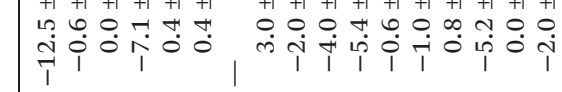

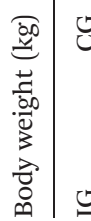

d.

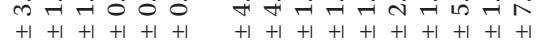

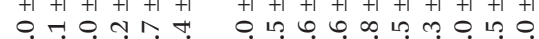

至

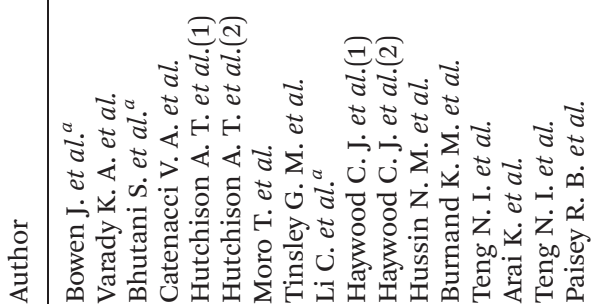




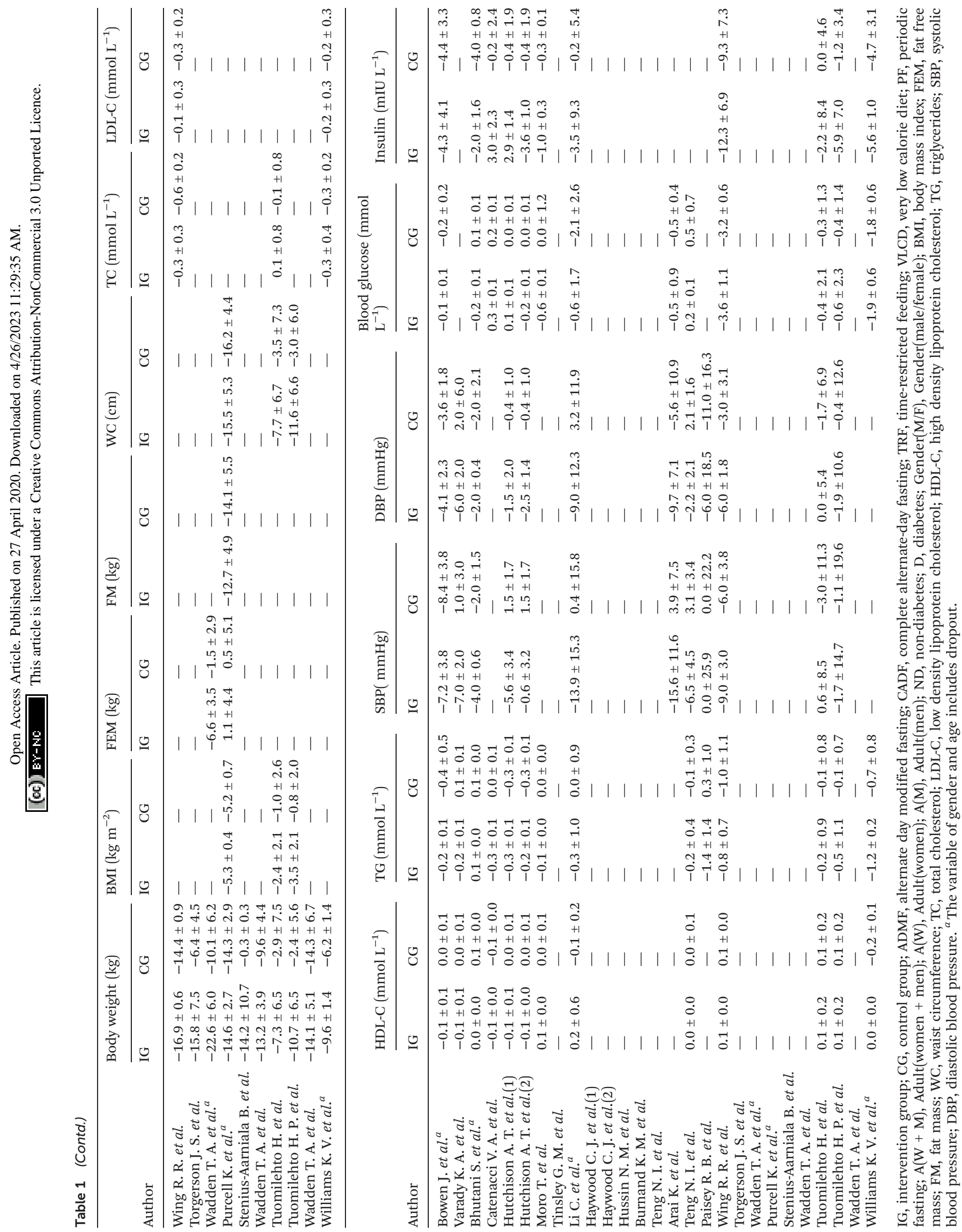


calculated. Exclusion criteria were as follows: (1) randomized studies were single-arm studies or without a placebo; (2) fasting due to religious habits; and (3) non-human studies, reviews and conference literature. Two researchers independently reviewed the literature and collected all eligible studies. Once disagreements existed, the nutritionist was involved to discuss and solve it (Fig. 1).

\subsection{Data abstraction}

Data collected from all included literature were as follows: (1) first author, nationality, publication year, numbers, mean age and gender of fasting intervention subjects and the control group; (2) the fasting type, subject type, fasting time and dose, diabetes or not, whether measured immediately after fasting or not (outcome type); and (3) the variations in the body weight, BMI, fat free mass (FEM), fat mass (FM), waist circumference (WC), total cholesterol (TC), low density lipoprotein cholesterol (LDL-C), high density lipoprotein cholesterol (HDL-C), triglycerides (TG), systolic blood pressure (SBP), dias- tolic blood pressure (DBP), blood glucose and insulin parameters in the fasting intervention and control subjects.

\subsection{Risk of bias within individual studies}

The methodological quality for the selected literature was evaluated independently using the Cochrane Collaboration (RevMan Version 5.3) software by two investigators according to Cochrane risk-of-bias criteria, ${ }^{21}$ which included seven items (randomization sequence generation, allocation concealment, blinding of participants and personnel, blinding of outcome assessment, incomplete outcome data, selective reporting, and other bias) to estimate bias in each trial. Each quality item was graded as low risk, unclear risk, or high risk. Simultaneously, the GRADE system was used to classify the quality of evidence. The included trials were graded as high quality, moderate quality, low quality, or very low quality according to the risk of bias, inconsistency, indirectness, imprecision and other considerations. $^{22}$

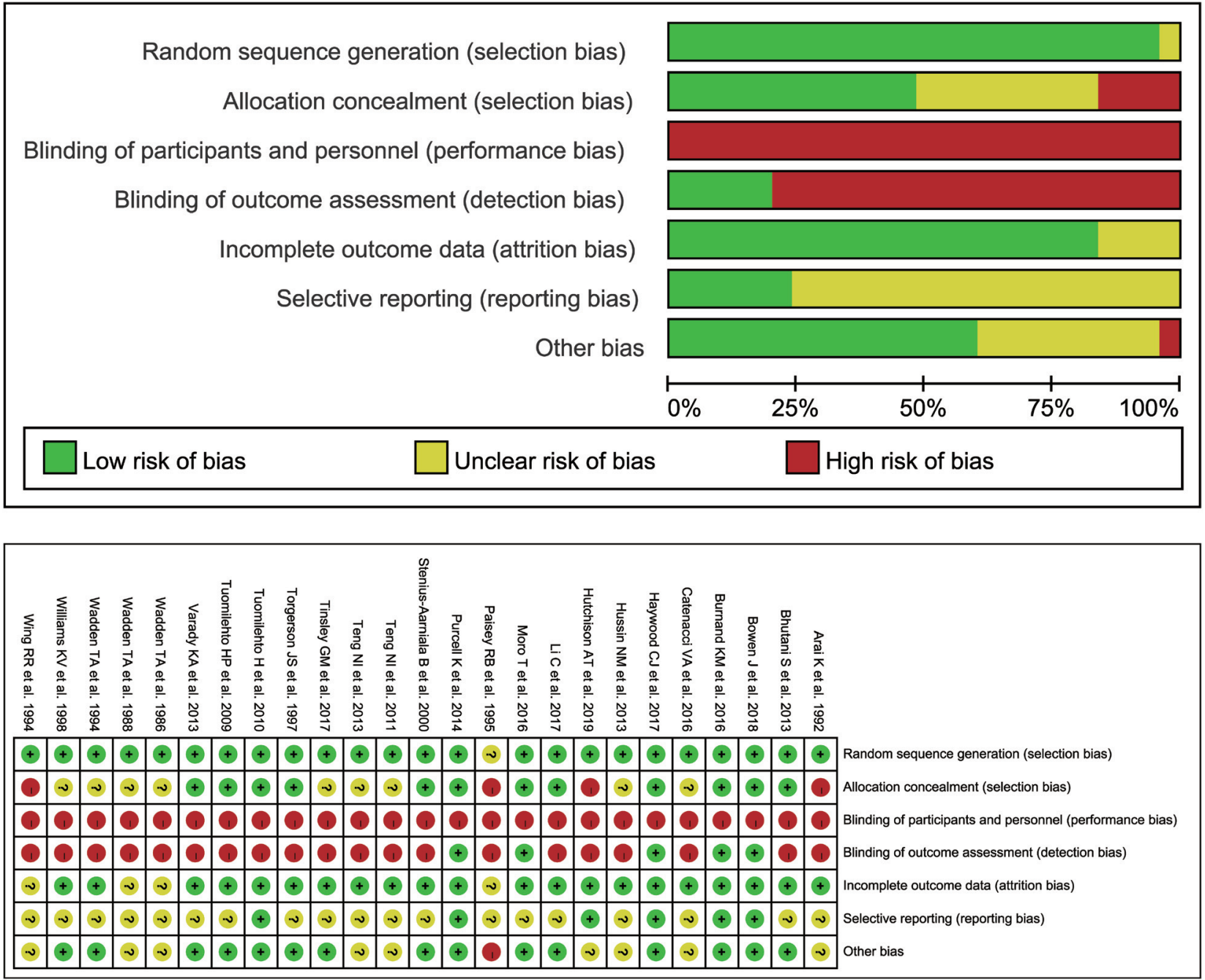

Fig. 2 Risk of within-study bias. 


\subsection{Statistical analysis}

Statistical analysis was performed using the statistical software Review Manager 5.3 and Stata 12.0. The mean change (standard deviation) in anthropometric and metabolic parameters from the baseline was used to evaluate the differences between the fasting intervention and control subjects. When it could not obtained via the original literature, we calculated the standard deviation in the mean change in the anthropometric and metabolic parameters using the formula in the Cochrane handbook. ${ }^{23}$ The correlation coefficient of the equation was estimated using the data from the included literature providing the baseline and endpoint values and the variations, simultaneously.

$$
\sqrt{\mathrm{SD}_{\text {Baseline }}{ }^{2}+\mathrm{SD}_{\text {Final }}{ }^{2}-\left(2 \times 0.98 \times \mathrm{SD}_{\text {Baseline }} \times \mathrm{SD}_{\text {Final }}\right)}
$$

The random effects model was used to compute the summary standard mean difference (SMD) and 95\% confidence interval (CI) and to evaluate the differences in the variations in the anthropometric and metabolic parameters between the fasting intervention group and the controls.

We use the $I^{2}$ statistic to estimate statistical heterogeneity. The potential publication bias was evaluated via the Egger test, where the trim-and-fill method (sensitivity analysis) was used to correct outcomes and evaluate the impact of bias on the outcomes. Subgroup analyses were conducted based on the fasting type (ADMF, CADF, TRF, VLCD), subject type (Adult (women + men), Adult(women), Adult(men)), Region(Oceania, America, Europe, Asia), fasting time ( $<12$ weeks, $\geq 12$ weeks), diabetes or not, and outcome type (follow-up, non follow-up). Because only one literature was for PF, the subgroup analysis was not conducted in view of PF.

\section{Results}

A total of 25 studies met inclusion criteria, involving 1358 samples, with 690 interventions and 668 controls. ${ }^{12,24-47}$ The variations in the body weight, BMI, FEM, FM, WC, TC, LDL-C, HDL-C, TG, SBP, DBP, blood glucose and insulin parameters were evaluated in twenty-four, ${ }^{12,24-27,29-47}$ thirteen, ${ }^{12,25,26,30,32-37,41,44,45}$ nine, ${ }^{12,24,25,27,28,34,36,40,41}$ ten, ${ }^{12,24-29,31,36,41}$ eight, ${ }^{25,27,30,31,37,41,44,45}$ thirteen, ${ }^{12,24-28,30,35-38,44,47}$ ten, ${ }^{12,24-28,30,34,38,47}$ twelve, ${ }^{12,24-28,30,36,38,44,45,47} \quad$ thirteen, ${ }^{12,24-28,30,36-38,44,45,47}$ eleven, ${ }^{12,24,25,27,30,35-38,44,45} \quad$ eleven, ${ }^{12,24,25,27,30,35-38,44,45}$ twelve $\mathrm{e}^{12,25-28,30,35,36,38,44,45,47}$ and ten ${ }^{12,25-28,30,38,44,45,47}$ studies, respectively. The detailed outcomes are performed in Table 1 and Table S2. $\dagger$ Almost all studies ${ }^{12,24-36,38-47}(n=24)$ were randomized, and nearly half of the studies ${ }^{12,24,25,28,30,31,33,39,41,42,44,45}(n=12)$ described allocation

Table 2 The summary of findings (SoF) with the GRADE system

Fasting intervention compared to no fasting intervention for regulating anthropometric and metabolic parameters

Population: subjects with overweight or obesity

Settings: four studies were conducted in Asia, eight studies were conducted in Europe, nine studies were conducted in America and four studies were conducted in Oceania

Intervention: fasting

Comparison: no fasting intervention

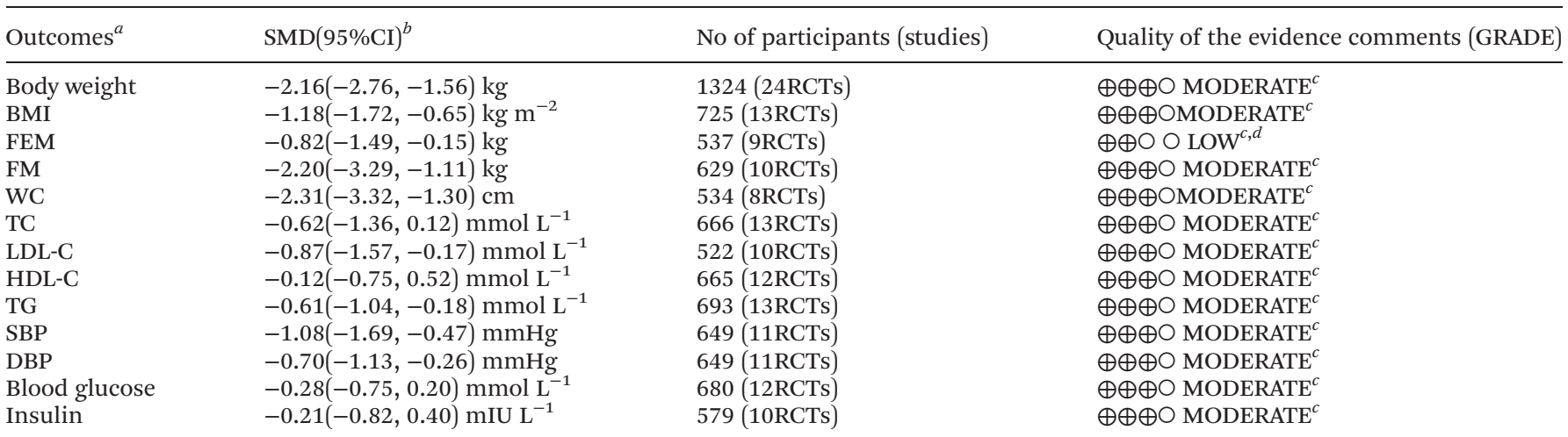

GRADE working group grades of evidence

High quality: We are very confident that the true effect lies close to that of the estimate of the effect

Moderate quality: We are moderately confident in the effect estimate: The true effect is likely to be close to the estimate of the effect, but there is a possibility that it is substantially different

Low quality: Our confidence in the effect estimate is limited: the true effect may be substantially different from the estimate of the effect Very low quality: We have very little confidence in the effect estimate: the true effect is likely to be substantially different from the estimate of effect

${ }^{a}$ All subjects were followed up from 1 week to 5 months. ${ }^{b}$ Results for variations of treatments compared with controls. SMD: standard mean deviation; CI: confidence interval; RCT: randomized controlled trial; BMI: body mass index; FEM: fat free mass; FM: fat mass; WC: waist circumference; TC: total cholesterol; LDL-C: low density lipoprotein cholesterol; HDL-C: high density lipoprotein cholesterol; TG: triglycerides; SBP: systolic blood pressure; DBP: diastolic blood pressure. ${ }^{c}$ Bias risk: Downgraded by one level as most of the included literature did not use the blind method (the main reason is that the intervention method cannot be blind). ${ }^{d}$ Inconsistency: Downgraded by one level as a high heterogeneity existed and its source was not completely clear. 
Study

ID

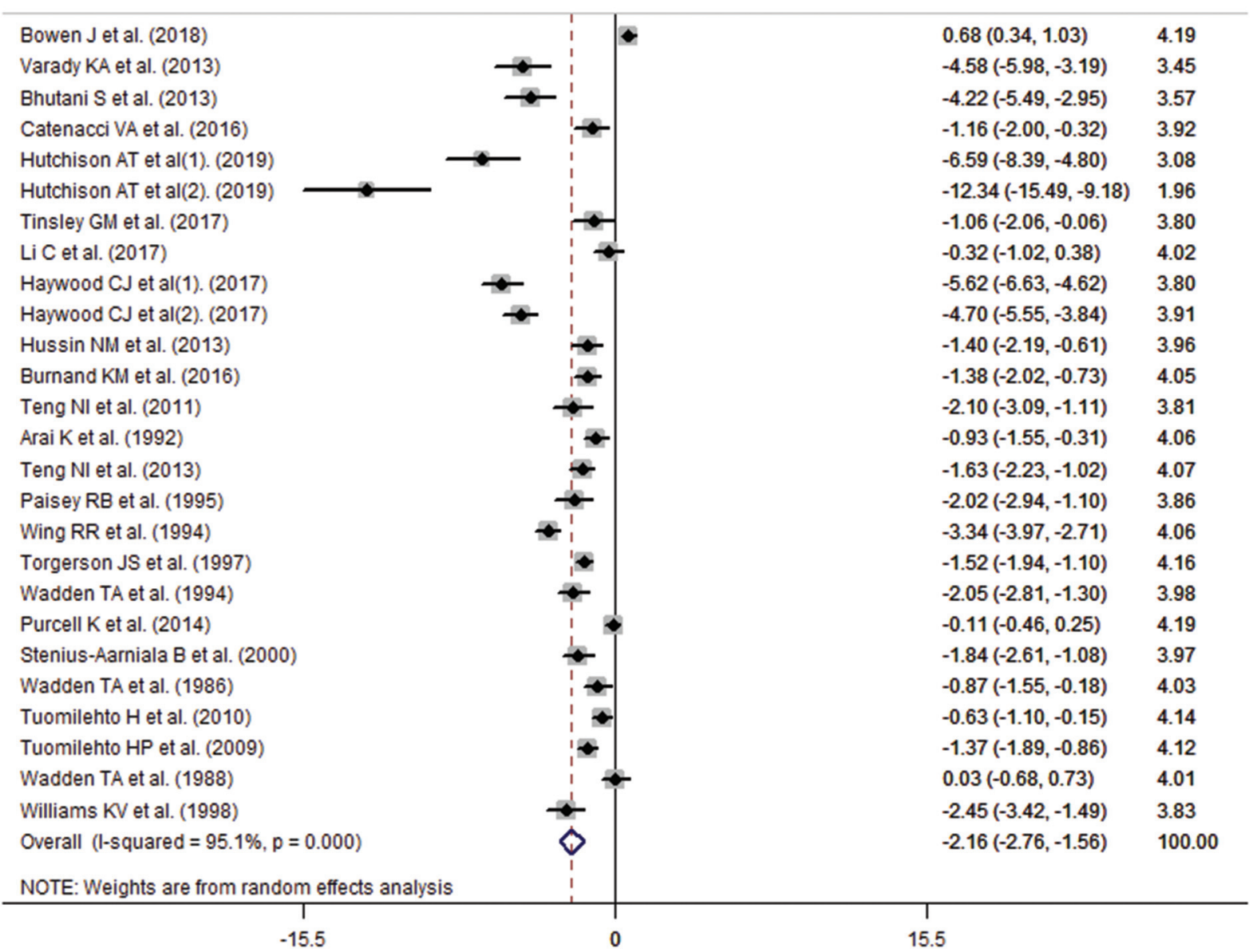

Fig. 3 Meta-analysis results of fasting intervention for the body weight in subjects with overweight or obesity.

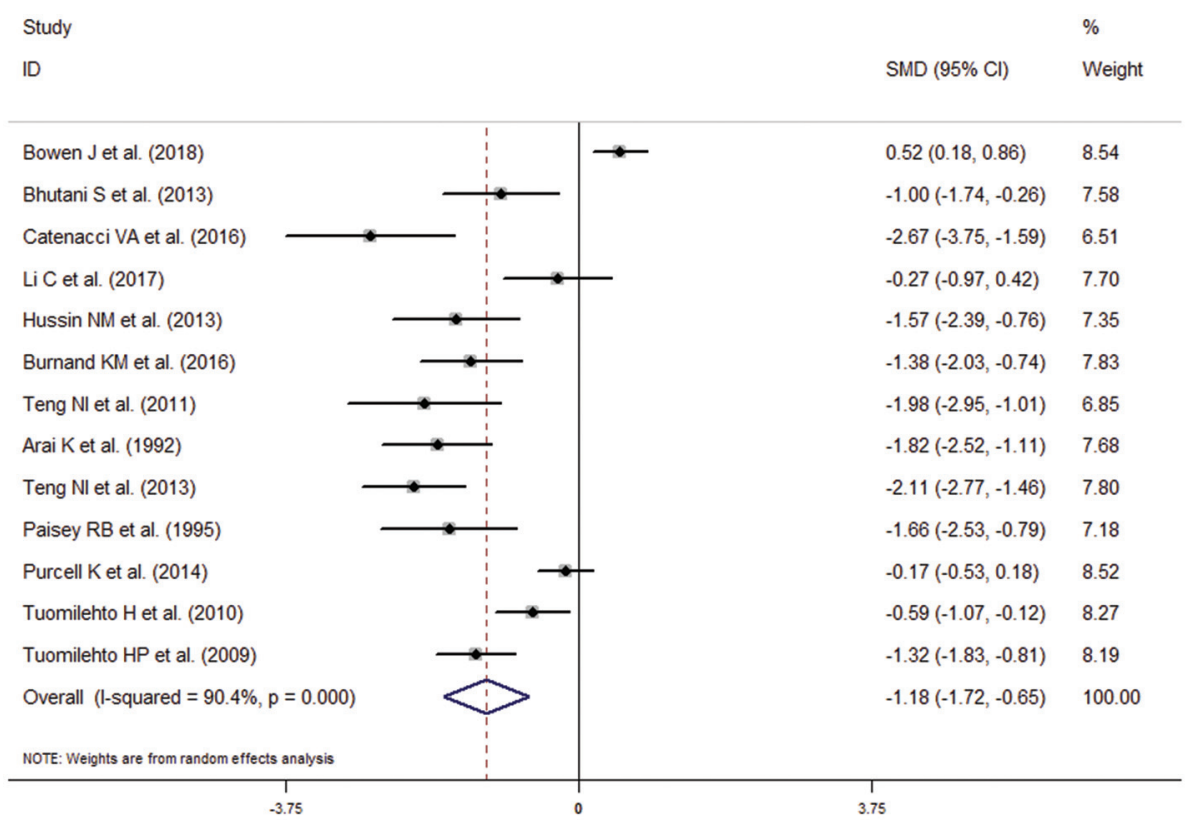

Fig. 4 Meta-analysis results of fasting intervention for the body mass index (BMI) in subjects with overweight or obesity. 
concealment methods. Specially, as fasting cannot blind between the intervention group and controls, double-blind setup were lacking in all studies. However, five studies stated that outcome assessments were blinded. ${ }^{12,28,31,33,41}$ Four studies were considered to have attrition bias as the reason for the drop out was not explained..$^{37,38,43,46}$ Only six trials had clinical trial registration codes, where reporting bias might have existed. ${ }^{12,27,31,33,41,44}$ After evaluation comprehensively, other biases existed in ten studies. ${ }^{26,27,32,34-38,43,46}$ The risk of bias within individual studies detailed is performed in Fig. 2.
In addition, the GRADE system was performed to determine the quality of evidence for different results. We considered that the grades of evidence were moderate quality in all outcomes except for the FEM parameter (low quality) (Table 2).

The meta-analysis revealed that fasting intervention led to a significantly larger weight loss $(\mathrm{SMD}=-2.16 \mathrm{~kg}, 95 \% \mathrm{CI}=$ $-2.76,-1.56 \mathrm{~kg}$; Fig. 3) compared with the control in subjects with overweight or obesity. Fasting intervention was associated with significantly larger reduction in BMI $(\mathrm{SMD}=-1.18 \mathrm{~kg}$ $\mathrm{m}^{-2}, 95 \% \mathrm{CI}=-1.72,-0.65 \mathrm{~kg} \mathrm{~m} \mathrm{~m}^{-2}$; Fig. 4), FEM (SMD =

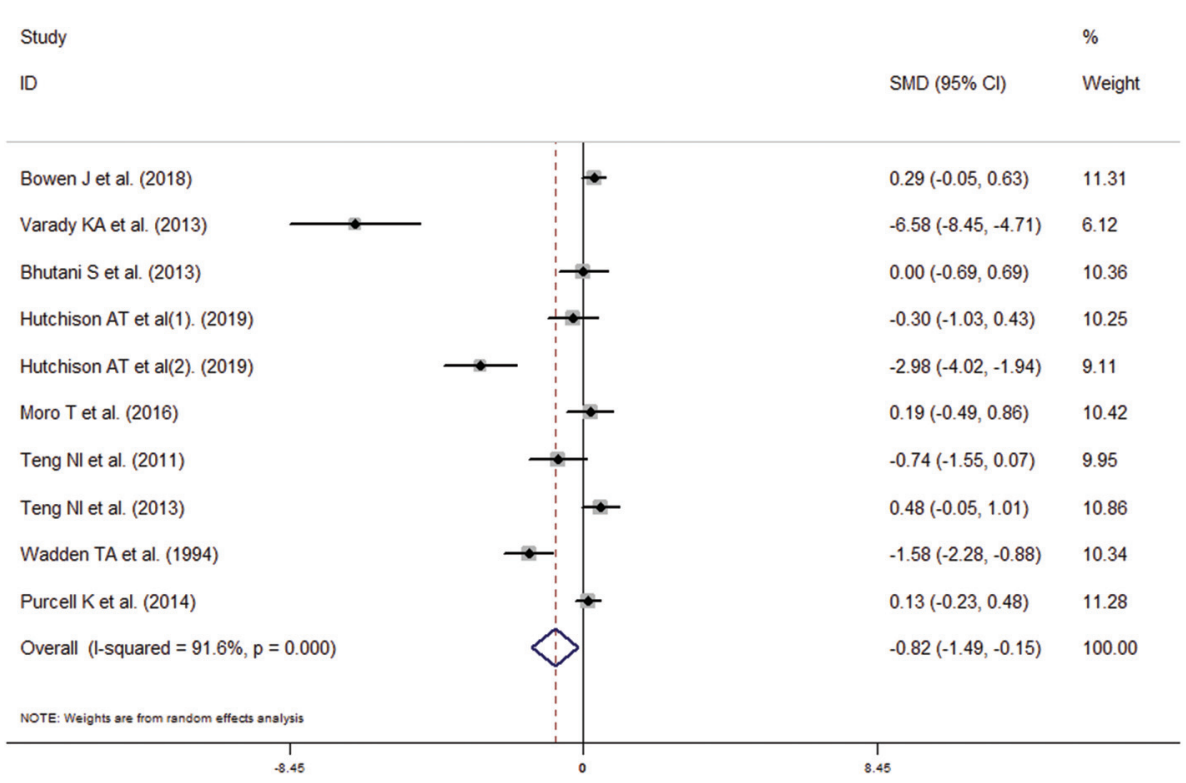

Fig. 5 Meta-analysis results of fasting intervention for the fat free mass (FEM) in subjects with overweight or obesity.

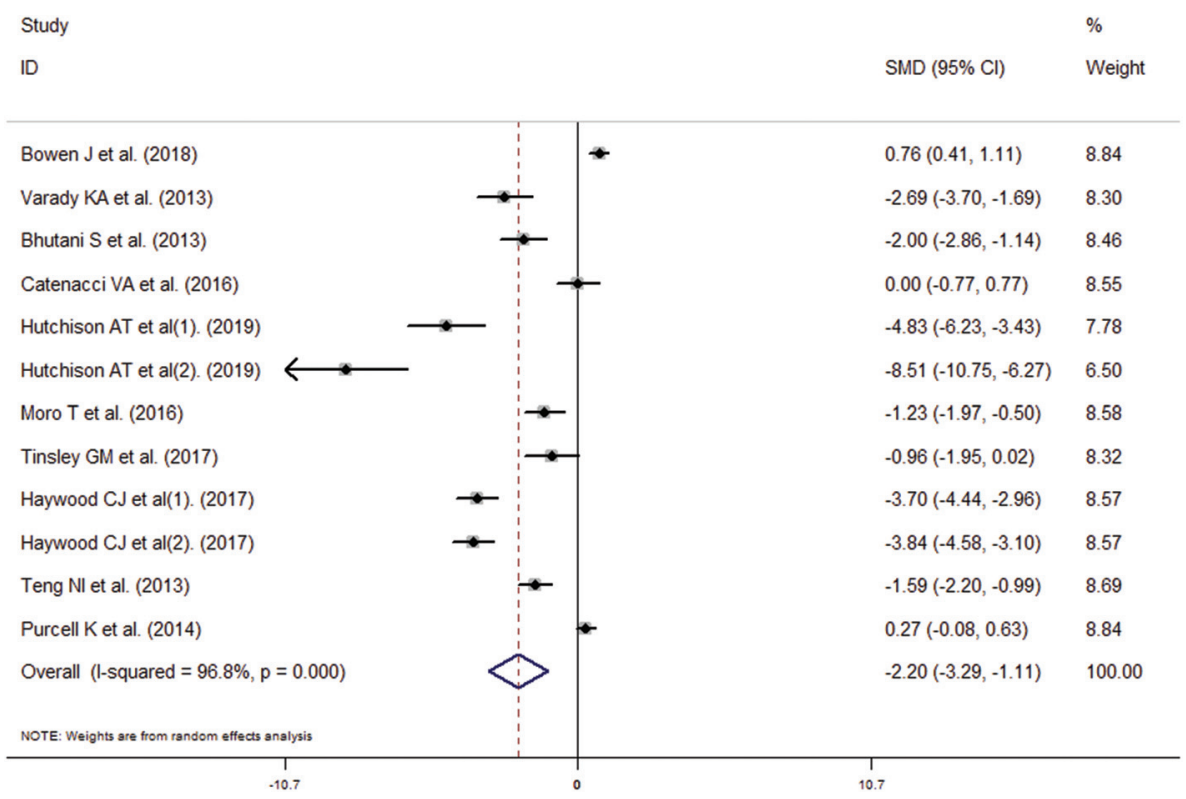

Fig. 6 Meta-analysis results of fasting intervention for the fat mass (FM) in subjects with overweight or obesity. 


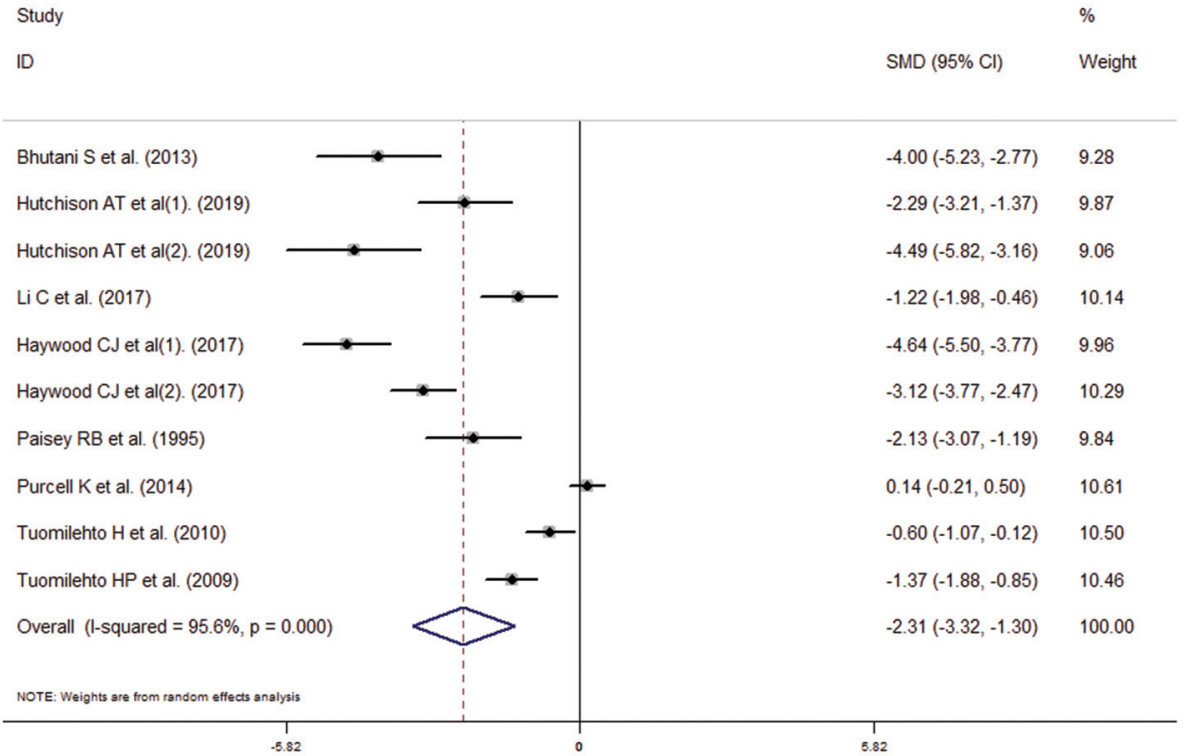

Fig. 7 Meta-analysis results of fasting intervention for the waist circumference (WC) in subjects with overweight or obesity.

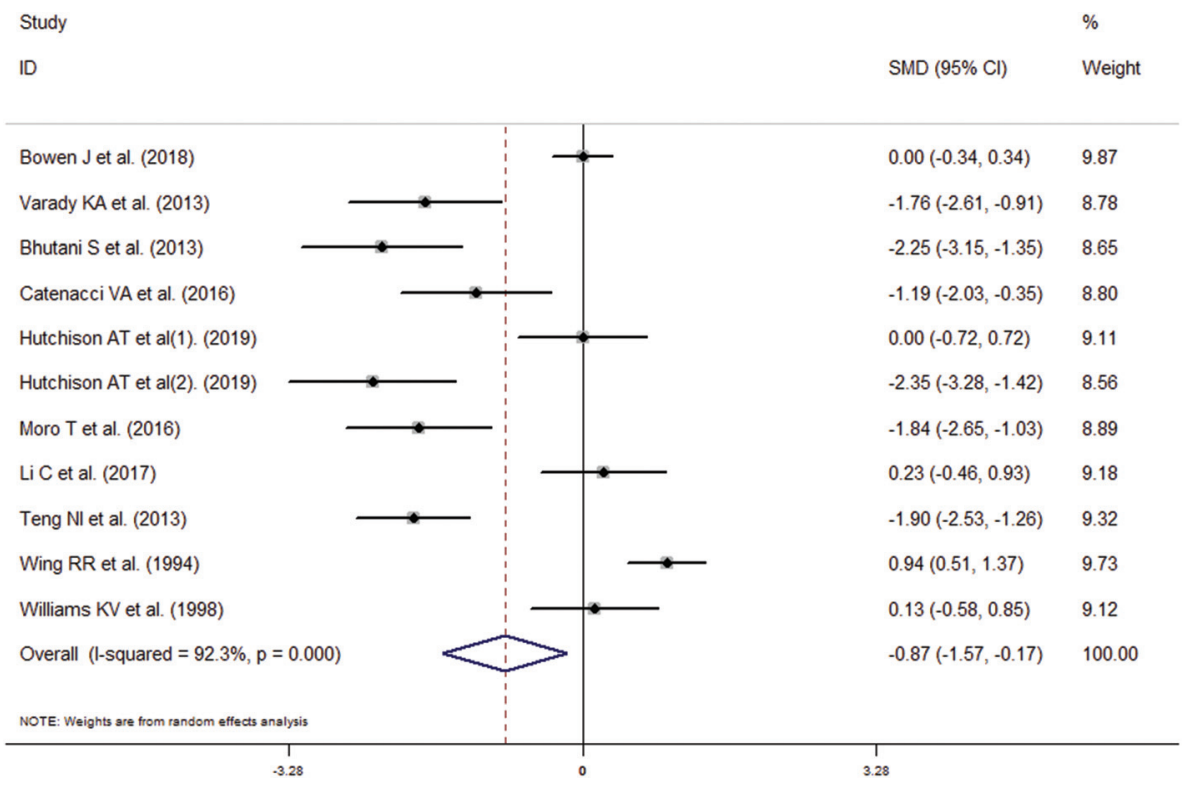

Fig. 8 Meta-analysis results of fasting intervention for the low density lipoprotein cholesterol (LDL-C) in subjects with overweight or obesity.

$-0.82 \mathrm{~kg}, 95 \% \mathrm{CI}=-1.49,-0.15 \mathrm{~kg} ;$ Fig. 5), FM (SMD = $-2.20 \mathrm{~kg}, 95 \% \mathrm{CI}=-3.29,-1.11 \mathrm{~kg} ;$ Fig. 6), and WC (SMD = $-2.31 \mathrm{~cm}, 95 \% \mathrm{CI}=-3.32,-1.30 \mathrm{~cm}$; Fig. 7). Meanwhile, statistically significant differences in the variations in the LDL-C $\left(\mathrm{SMD}=-0.87 \mathrm{mmol} \mathrm{L}{ }^{-1}, 95 \% \mathrm{CI}=-1.57,-0.17 \mathrm{mmol} \mathrm{L}^{-1}\right.$; Fig. 8), TG (SMD $=-0.61 \mathrm{mmol} \mathrm{L} \mathrm{L}^{-1}, 95 \%$ CI $=-1.04$, $-0.18 \mathrm{mmol} \mathrm{L}^{-1}$; Fig. 9), SBP (SMD $=-1.08 \mathrm{mmHg}, 95 \% \mathrm{CI}=$ $-1.69,-0.47 \mathrm{mmHg}$; Fig. 10), and DBP (SMD $=-0.70 \mathrm{mmHg}$, $95 \%$ CI $=-1.13,-0.26 \mathrm{mmHg}$; Fig. 11) parameters were noticed between the intervention groups and the controls. However, the data obtained from the included literature did not indicate any significant effect of fasting on the TC (SMD = $-0.62 \mathrm{mmol} \mathrm{L}^{-1}$, 95\% CI $=-1.36,0.12 \mathrm{mmol} \mathrm{L}{ }^{-1}$; Fig. 12), HDL-C (SMD $=-0.12 \mathrm{mmol} \mathrm{L}^{-1}, 95 \% \mathrm{CI}=-0.75,0.52 \mathrm{mmol}$ $\mathrm{L}^{-1}$; Fig. 13), blood glucose $\left(\mathrm{SMD}=-0.28 \mathrm{mmol} \mathrm{L}^{-1}, 95 \% \mathrm{CI}=\right.$ $-0.75,0.20 \mathrm{mmol} \mathrm{L}^{-1}$; Fig. 14) and insulin (SMD $=-0.21 \mathrm{mIU}$ $\mathrm{L}^{-1}, 95 \% \mathrm{CI}=-0.82,0.40 \mathrm{mIU} \mathrm{L}{ }^{-1}$; Fig. 15) concentrations.

The outcomes of subgroup analyses for fasting intervention and the change of anthropometric and metabolic parameters in the people with overweight or obesity are summarized in Table 3. Region may be the sources of heterogeneity for body weight, BMI, TC and SBP in the associated studies. Subject 


\begin{tabular}{|c|c|c|c|}
\hline Study & & & $\%$ \\
\hline ID & & SMD $(95 \% \mathrm{Cl})$ & Weight \\
\hline Bowen J et al. (2018) & $\rightarrow$ & $0.54(0.19,0.88)$ & 8.30 \\
\hline Varady KA et al. (2013) & & $-3.47(-4.63,-2.32)$ & 5.34 \\
\hline Bhutani S et al. (2013) & & $0.00(-0.69,0.69)$ & 7.13 \\
\hline Catenacci VA et al. (2016) & & $-1.99(-2.95,-1.04)$ & 6.10 \\
\hline Hutchison AT et al(1). (2019) & & $-0.27(-1.00,0.46)$ & 7.00 \\
\hline Hutchison AT et al(2). (2019) & & $0.13(-0.59,0.85)$ & 7.01 \\
\hline Moro T et al. (2016) & & $-1.54(-2.31,-0.77)$ & 6.82 \\
\hline Li C et al. (2017) & & $-0.28(-0.98,0.41)$ & 7.11 \\
\hline Teng NI et al. (2013) & & $-0.39(-0.92,0.14)$ & 7.73 \\
\hline Paisey RB et al. (1995) & & $-1.40(-2.24,-0.57)$ & 6.58 \\
\hline Wing RR et al. (1994) & $\leftarrow$ & $0.22(-0.19,0.63)$ & 8.12 \\
\hline Tuomilehto $\mathrm{H}$ et al. (2010) & & $-0.12(-0.58,0.35)$ & 7.94 \\
\hline Tuomilehto HP et al. (2009) & & $-0.46(-0.93,0.01)$ & 7.93 \\
\hline Williams KV et al. (1998) & & $-0.86(-1.61,-0.11)$ & 6.90 \\
\hline Overall (I-squared $=85.8 \%, p=0.000$ ) & & $-0.61(-1.04,-0.18)$ & 100.00 \\
\hline NOTE: Weights are from random effects analysis & & & \\
\hline
\end{tabular}

Fig. 9 Meta-analysis results of fasting intervention for the triglycerides (TG) in subjects with overweight or obesity.

\begin{tabular}{|c|c|c|c|}
\hline \multicolumn{2}{|l|}{ Study } & \multirow[b]{2}{*}{$\operatorname{SMD}(95 \% \mathrm{Cl})$} & \multirow{2}{*}{$\begin{array}{l}\% \\
\text { Weight }\end{array}$} \\
\hline ID & & & \\
\hline Bowen J et al. (2018) & $\rightarrow$ & $0.32(-0.02,0.66)$ & 9.09 \\
\hline Varady KA et al. (2013) & & $-3.14(-4.23,-2.05)$ & 7.22 \\
\hline Bhutani S et al. (2013) & & $-1.77(-2.59,-0.94)$ & 8.00 \\
\hline Hutchison AT et al(1). (2019) & & $-2.40(-3.34,-1.46)$ & 7.68 \\
\hline Hutchison AT et al(2). (2019) & & $-0.75(-1.50,-0.00)$ & 8.21 \\
\hline Li C et al. (2017) & & $-0.92(-1.65,-0.19)$ & 8.26 \\
\hline Arai Ket al. (1992) & & $-2.04(-2.77,-1.32)$ & 8.26 \\
\hline Teng Nl et al. (2013) & & $-2.40(-3.10,-1.71)$ & 8.36 \\
\hline Paisey RB et al. (1995) & & $0.00(-0.74,0.74)$ & 8.23 \\
\hline Wing RR et al. (1994) & & $-0.88(-1.30,-0.45)$ & 8.95 \\
\hline Tuomilehto $\mathrm{H}$ et al. (2010) & $\rightarrow$ & $0.36(-0.11,0.83)$ & 8.87 \\
\hline Tuomilehto HP et al. (2009) & & $-0.03(-0.50,0.43)$ & 8.88 \\
\hline Overall (1-squared $=92.1 \%, p=0.000$ ) & & $-1.08(-1.69,-0.47)$ & 100.00 \\
\hline NOTE: Weights are from random effects analysis & & & \\
\hline
\end{tabular}

Fig. 10 Meta-analysis results of fasting intervention for the systolic blood pressure (SBP) in subjects with overweight or obesity.

type may be the sources of heterogeneity for FM and LDL-C and outcome type may be the sources of heterogeneity for TG, blood glucose, WC and insulin. In addition, fasting type may be the sources of heterogeneity for HDL-C and fasting time may be the sources of heterogeneity for DBP.

The results of publication bias for included studies are given in Table 4. Publication biases were observed in the body weight, BMI, FEM, FM, WC, TC, LDL-C and SBP $(P<0.05)$. However, there was no significant difference between the SMD and that before the trim and fill. Therefore, the effect of publi- cation bias was considered slight and the results were stable (Table 4).

\section{Discussion}

According to the existing evidence of relevant animal and human studies, fasting has a beneficial effect on advancing health and reduces the risk of several chronic illnesses in adults, especially for overweight and sedentary people. ${ }^{6}$ 
Study

ID
$\%$

Weight

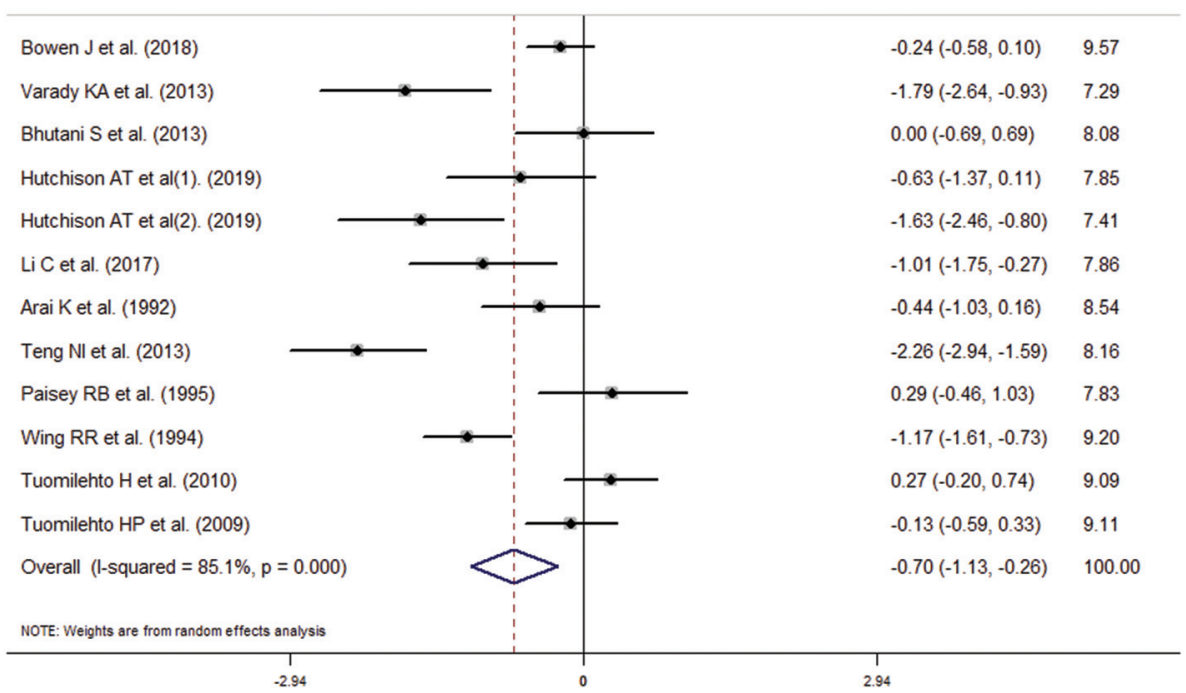

Fig. 11 Meta-analysis results of fasting intervention for the diastolic blood pressure (DBP) in subjects with overweight or obesity.

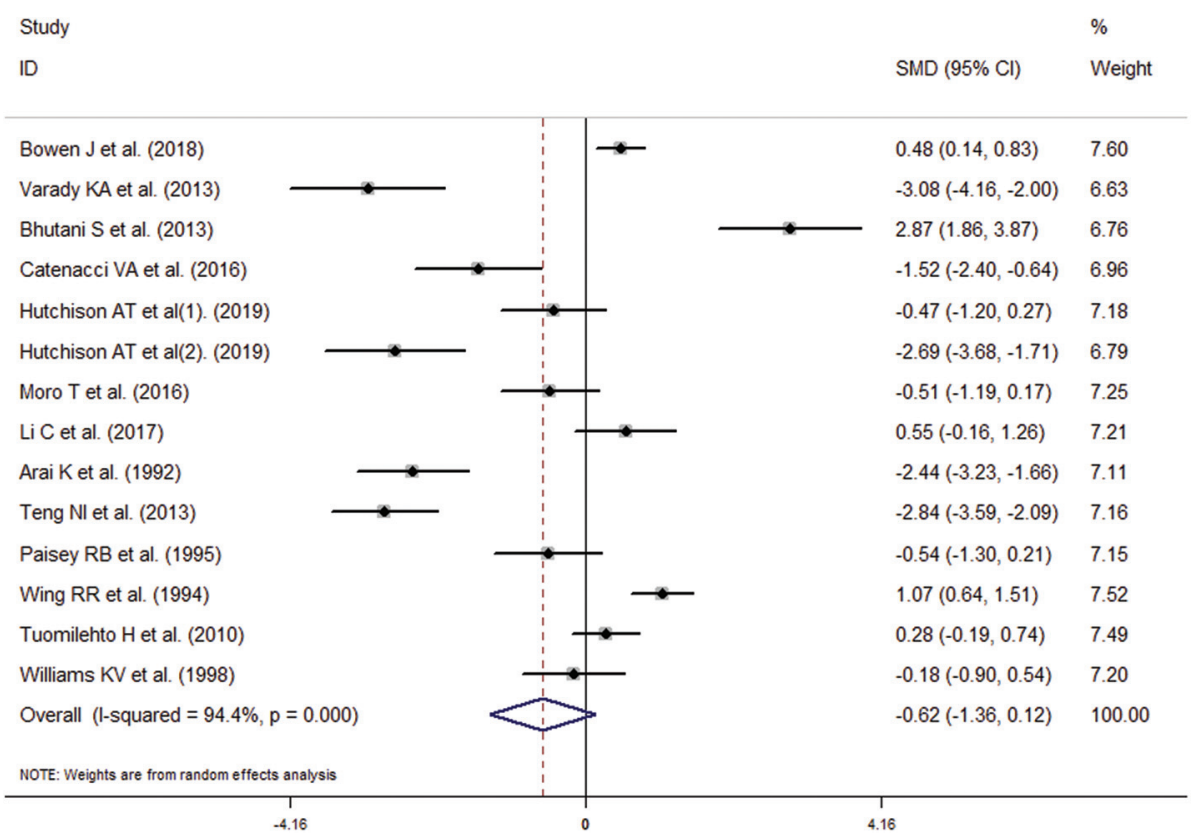

Fig. 12 Meta-analysis results of fasting intervention for the total cholesterol (TC) in subjects with overweight or obesity.

Similarly, our study found that participants with overweight or obesity receiving fasting intervention had significantly larger reductions in body weight, BMI, FEM, FM, WC, LDL-C, TG, SBP and DBP parameters than the control subjects. One crucial mechanism resulting in these profitable influences seems to be "flipping" of the metabolic switch. ${ }^{8}$ When the hepatic glycogen is depleted due to fasting, some metabolic adaptations are observed in the liver, thus retaining systemic energy balance and supplying the major organs, tissues and cells with sufficient nutrients. ${ }^{48}$ The characteristics are increased numbers of circulating ketones, whereas circulating fatty acids, amino acids, glucose, and insulin are preserved at low concentrations. ${ }^{49}$ And it is owing to the fat mobilization and the oxidative decomposition of fatty acids. ${ }^{50,51}$ Ketones are metabolized to acetyl coenzyme A, which then enters the tricarboxylic acid (TCA) cycle to generate ATP, thus serving as an energy source to sustain the function of muscle and brain cells during fasting. ${ }^{51}$ In other words, the primary energy source for the body shifts from glucose to free fatty acids derived from adipose tissue lipolysis and ketones, which means "flipping" 


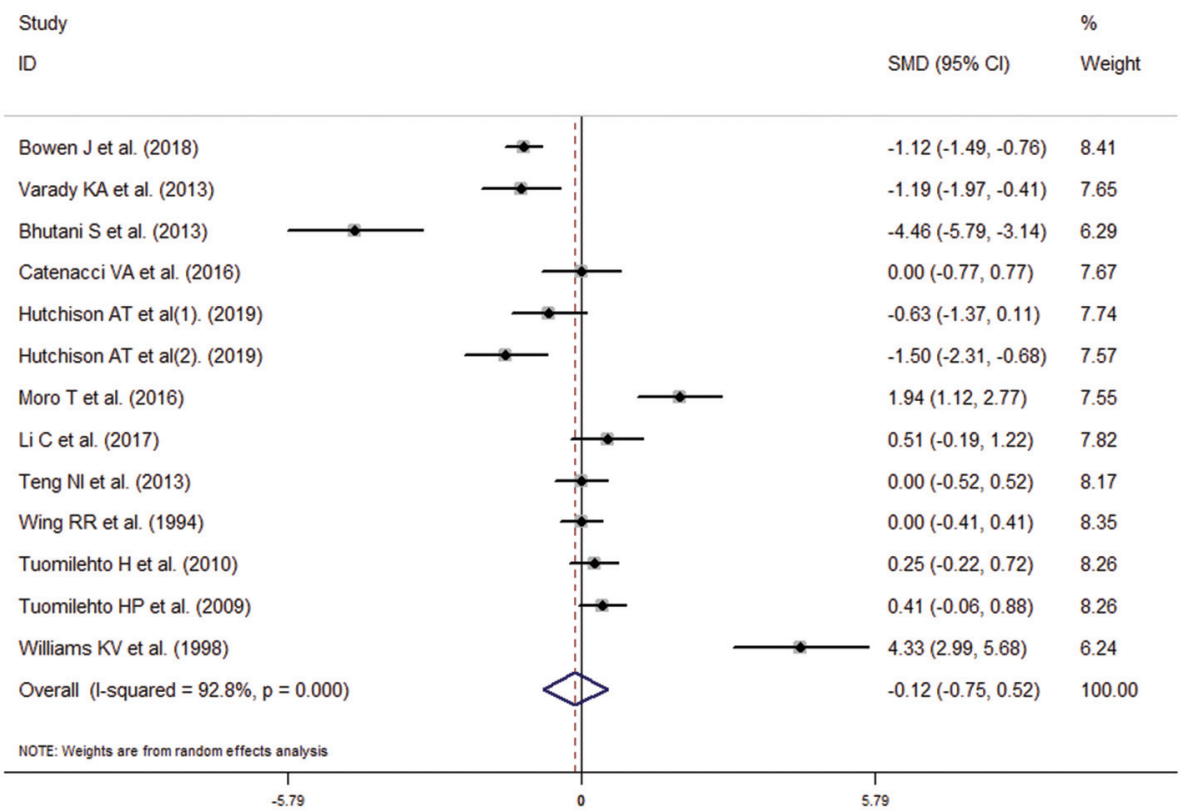

Fig. 13 Meta-analysis results of fasting intervention for the high density lipoprotein cholesterol (HDL-C) in subjects with overweight or obesity.

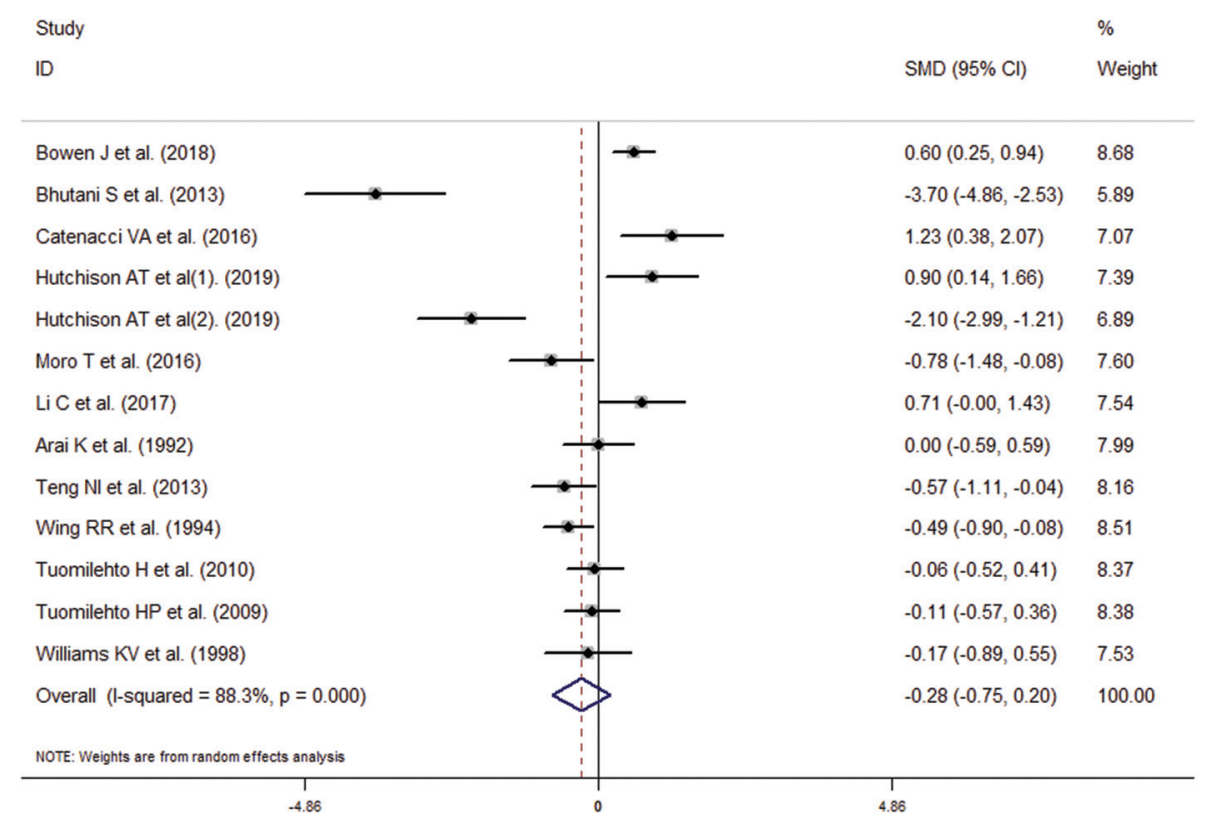

Fig. 14 Meta-analysis results of fasting intervention for the blood glucose in subjects with overweight or obesity.

of the metabolic switch. ${ }^{8}$ For this reason, fasting may have a potential effect on the regulation of obesity and related metabolic parameters.

The existence of small LDL particles and higher post-prandial hyperlipemia are markers of myocardial infarction (MI) and ischemic heart disease (IHD) progression. ${ }^{52,53}$ Our study found that the fasting intervention group had significant decreases more in LDL-C, and TG parameters than the control group. Recent clinic trials have demonstrated that alternate day fasting could reduce the ratio of small LDL particles, thereby causing the reduction of LDL-C and TG parameters. ${ }^{25,54}$ Meanwhile, weight loss may also be an important factor. Previous literature indicated that only subjects with more weight loss had a significant blood lipid decrease, as with blood pressure. ${ }^{8}$ Similarly, in view of our outcomes of the subgroup meta-analysis, after fasting was stopped for a period of time, the amount of weight loss was smaller based on SMD values. Correspondingly, the variations in blood lipids and blood pressure between the fasting intervention subjects and controls change to no statistically significant differences. 


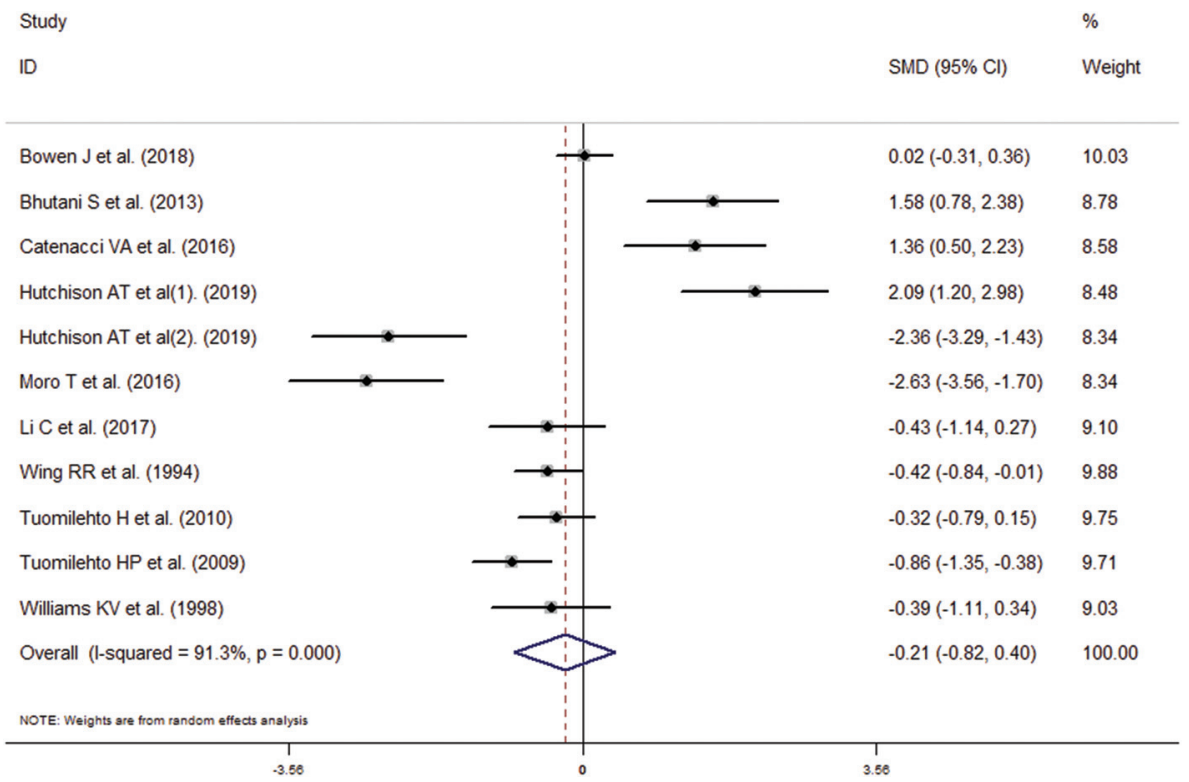

Fig. 15 Meta-analysis results of fasting intervention for the insulin in subjects with overweight or obesity.

Based on the outcomes of the subgroup meta-analysis, apart from HDL-C, blood glucose and insulin, the anthropometric and metabolic parameters had a larger reduction in the CADF group than the VLCD group in view of SMD values (especially at body weight, WC, TC and DBP parameters). Although the previous literature showed that the differences between intermittent and continuous energy restriction were not observed in boosting weight reduction and metabolic improvements, our study especially indicated that CADF is more effective in regulating anthropometric and metabolic parameters than VLCD for people with overweight or obesity. ${ }^{55}$ The possible mechanisms include improving autophagy via sirtuin-1 activity stimulation, changing cell apoptosis, increasing the expression of vascular endothelial growth factor (VEGF), and reducing glycosylation end products. ${ }^{56-59}$ Meanwhile, some studies indicated that subjects of IF usually did not take enough energy in the normal diet period to compensate for the fasting period, thus indicating that IF could decrease the total energy intake. ${ }^{8,60}$ In addition, the incidence of adverse events of short-term intermittent fasting was lower than that of long-term fasting. ${ }^{8}$ Similarly, the results of subgroup analysis indicated no differences in the influence of fasting time on regulating anthropometric and metabolic parameters. Therefore, short-term CADF may be a better choice for people with overweight or obesity. However, as previous studies have shown, due to differences in trial design, participant characteristics, and subject compliance, as well as limited sample size and studies, more clinic trials are needed to estimate the role of CADF in people with overweight or obesity. ${ }^{61}$

Although the differences between the fasting intervention and control subjects were not found in the variations in the insulin parameter, significant differences were noticed for the VLCD intervention in view of subgroup analysis. It is univer- sally known that weight gain and obesity are critical risk factors in terms of insulin resistance. ${ }^{62}$ Simultaneously, insulin-resistant patients with obesity need more insulin to regulate blood glucose, leading to weight gain progressively, thus a vicious circle formation. ${ }^{63}$ Previous studies found that the VLCD could normalize insulin sensitivity and total insulin secretion via reducing the hepatic and pancreatic fat. ${ }^{64}$ Meanwhile, as an anabolic hormone, insulin could induce cell growth and advance the storage of fatty acids in adipose and muscle tissue, irritating muscle hypertrophy and restraining proteolysis. $^{65,66}$ Therefore, the insulin secretion returns to normal and can reduce body weight and a virtuous circle is established. Correspondingly, fasting intervention can effectively improve patients with obesity and diabetes through the dual regulation of body weight and insulin levels in terms of the outcomes of subgroup analysis. Moreover, statistically significant differences in the variations in insulin parameter were noticed between the fasting intervention and control subjects after fasting was stopped for a period of time. This beneficial effect may result from a cellular stress response induced by the fasting state. However, the theory has been proved only in animal experiments, human trials are needed. ${ }^{67}$

This study has some limitations. The blind method is not applicable to all included studies due to the intervention contents and methods for participants and nutritionists could not be masked. Although the research staff of some studies evaluating the outcome were unaware of the apportion of the participants, true intervention effects could be biased by the restricted quality of the methodology.$^{68}$ Meanwhile, the heterogeneity of most results is high. The reasons may be the differences of subjects and region, as well as the outcome type and other factors. In addition, due to the lack of control or changes before and after the intervention in many studies, there are few studies of IF meeting the inclusion criteria. 
Table 3 Subgroup analyses were performed for anthropometric and metabolic parameters

\begin{tabular}{|c|c|c|c|c|c|c|c|c|c|c|c|c|c|}
\hline \multirow[b]{2}{*}{ Factors } & \multicolumn{13}{|c|}{ Number of studies } \\
\hline & BW & BMI & FEM & FM & WC & $\mathrm{TC}$ & LDL-C & HDL-C & TG & SBP & DBP & BG & Insulin \\
\hline \multicolumn{14}{|l|}{ Fasting type } \\
\hline $\mathrm{ADMF}$ & 3 & 2 & 3 & 3 & - & 3 & 3 & 3 & 3 & 3 & 3 & 2 & 2 \\
\hline CADF & 2 & - & 1 & 2 & 1 & 2 & 2 & 2 & 2 & 1 & 1 & 2 & 2 \\
\hline TRF & - & - & - & 2 & - & - & - & - & - & - & - & - & - \\
\hline VLCD & 17 & 10 & 4 & 3 & 6 & 6 & 3 & 5 & 6 & 7 & 7 & 6 & 4 \\
\hline \multicolumn{14}{|l|}{ Subjects } \\
\hline Adult(W + M) & 18 & 10 & 4 & 6 & 7 & 10 & 7 & 9 & 10 & 9 & 9 & 9 & 8 \\
\hline Adult(W) & 2 & - & 2 & 1 & 1 & 1 & 1 & 1 & 1 & 1 & 1 & 1 & 1 \\
\hline Adult(M) & 4 & 3 & 3 & 3 & - & 2 & 2 & 2 & 2 & - & - & 2 & - \\
\hline \multicolumn{14}{|l|}{ Outcome type } \\
\hline NF & 16 & 9 & - & - & 5 & 9 & 7 & 7 & 8 & 7 & 7 & 7 & 5 \\
\hline $\mathrm{F}$ & 8 & 4 & - & - & 3 & 4 & 3 & 5 & 5 & 4 & 4 & 5 & 5 \\
\hline \multicolumn{14}{|l|}{ Fasting time } \\
\hline$<12$ weeks & 9 & 4 & 2 & 4 & 2 & 5 & 4 & 4 & 4 & 3 & 3 & 5 & 4 \\
\hline$\geq 12$ weeks & 15 & 9 & 7 & 6 & 6 & 8 & 6 & 8 & 9 & 8 & 8 & 7 & 6 \\
\hline \multicolumn{14}{|l|}{ Region } \\
\hline Oceania & 4 & 2 & 3 & 4 & 3 & 2 & 2 & 2 & 2 & 2 & 2 & 2 & 2 \\
\hline America & 10 & 2 & 3 & 4 & - & 5 & 5 & 5 & 5 & 3 & 3 & 4 & 4 \\
\hline Europe & 7 & 5 & - & - & 4 & 4 & 2 & 4 & 5 & 4 & 4 & 4 & 4 \\
\hline Asia & 4 & 4 & 2 & - & - & 2 & - & - & - & 2 & 2 & 2 & - \\
\hline \multicolumn{14}{|l|}{ Diabetes } \\
\hline No & 20 & 11 & - & - & 6 & 9 & 7 & 9 & 9 & 8 & 8 & 9 & 7 \\
\hline \multirow[t]{2}{*}{ Yes } & 4 & 2 & - & - & 2 & 4 & 3 & 3 & 4 & 3 & 3 & 3 & 3 \\
\hline & \multicolumn{13}{|c|}{ Standard mean difference ( $95 \% \mathrm{CI}), P$} \\
\hline Factors & \multicolumn{3}{|l|}{ BW } & \multicolumn{4}{|c|}{ BMI } & \multicolumn{3}{|l|}{ FEM } & \multicolumn{3}{|l|}{ FM } \\
\hline \multicolumn{14}{|l|}{ Fasting type } \\
\hline $\mathrm{ADMF}$ & \multirow{2}{*}{\multicolumn{3}{|c|}{$\begin{array}{l}-2.67(-6.67,1.34), 0.192 \\
-6.53(-12.33,-0.73), 0.027\end{array}$}} & \multicolumn{4}{|c|}{$-0.20(-1.69,1.29), 0.790$} & $-1.78(-3.9$ & $.37), 0$. & & $-1.28(-$ & $57,1.11$ & 0.295 \\
\hline $\mathrm{CADF}$ & & & & & - & & & $-1.61(-4.2$ & $1.02), 0$. & & $-4.36(-$ & $13,0.42$ & 0.074 \\
\hline TRF & - & & & & - & & & - & & & $-1.14(-$ & $73,-0$. &,$<0.001$ \\
\hline VLCD & -1.7 & $-2.31,-$ & 5), $<0.001$ & & $-1.25(-1.7$ & $-0.76)$, & .001 & $-0.39(-1.2$ & $.44), 0$. & & $-2.20(-$ & $31,-0$. & 0.042 \\
\hline Subjects & & & & & & & & & & & & & \\
\hline Adult(W + M) & -1.8 & $-2.53,-$ & 7), $<0.001$ & & $-0.97(-1.5$ & $-0.40)$, & 001 & $-0.94(-2.0$ & 0.17), 0. & & $-1.58(-$ & $0,-0.1$ & 0.030 \\
\hline Adult(W) & -6.8 & -11.97 & $62), 0.010$ & & - & & & $-1.58(-2.9$ & $-0.18)$ & 27 & $-6.56(-$ & $16,-2$ & ), $<0.001$ \\
\hline Adult(M) & -1.5 & $-1.95,-$ & $6),<0.001$ & & $-1.92(-2.3$ & $-1.46)$, & .001 & $0.03(-0.64$ & 70), 0.92 & & $-1.36(-$ & $78,-0$. & $<0.001$ \\
\hline Outcome type & & & & & & & & & & & & & \\
\hline NF & -2.5 & $-3.42,-$ & 5), $<0.001$ & & $-1.34(-2.1$ & $-0.56)$, & 001 & - & & & - & & \\
\hline $\mathrm{F}$ & -1.4 & $-2.15,-$ & $5),<0.001$ & & $-0.90(-1.4$ & $-0.39)$, & 001 & - & & & - & & \\
\hline Fasting time & & & & & & & & & & & & & \\
\hline$<12$ weeks & -1.9 & $-2.85,-$ & 4), $<0.001$ & & $-1.48(-2.3$ & $-0.59)$, & 001 & $-0.99(-2.6$ & $.68), 0$. & & $-2.88(-$ & $0,-0$. & 0.005 \\
\hline$\geq 12$ weeks & -2.2 & $-3.06,-$ & $5),<0.001$ & & $-1.05(-1.6$ & $-0.42)$ & 001 & $-0.75(-1.5$ & $.02), 0$. & & $-1.80(-$ & $21,-0.3$ & 0.012 \\
\hline Region & & & & & & & & & & & & & \\
\hline Oceania & -4.3 & $-6.64,-$ & 5), $<0.001$ & & $0.18(-0.51$ & 86), 0.6 & & $-0.57(-1.4$ & ..31), 0. & & $-3.12(-$ & $7,-1.1$ & 0.002 \\
\hline America & -2.1 & $-3.09,-$ & 7), $<0.001$ & & $-1.78(-3.4$ & $-0.15)$, & 032 & $-2.52(-5.0$ & $-0.03)$ & & $-1.39(-$ & $59,-0.2$ & 0.022 \\
\hline Europe & -1.2 & $-1.68,-$ & 4), $<0.001$ & & $-1.02(-1.5$ & $-0.54)$, & .001 & - & & & - & & \\
\hline Asia & -1.4 & $-1.89,-$ & 9), $<0.001$ & & $-1.89(-2.2$ & -1.51), & .001 & $-0.09(-1.2$ & 1.11), 0. & & - & & \\
\hline Diabetes & & & & & & & & & & & & & \\
\hline No & -2.1 & $-2.84,-$ & 3), $<0.001$ & & $-1.23(-1.8$ & $-0.63)$, & .001 & - & & & - & & \\
\hline Yes & -2.0 & $-3.47,-$ & $0), 0.006$ & & $-0.94(-2.3$ & $0.42), 0$ & & - & & & - & & \\
\hline
\end{tabular}

Standard mean difference (95\% CI), $P$

\begin{tabular}{lllll} 
Factors & WC & TC & LDL-C & HDL-C \\
\hline Fasting type & & & & $-2.11(-3.59,-0.64), 0.005$ \\
$\quad$ ADMF & - & $0.10(-2.47,2.68), 0.937$ & $-1.30(-2.86,0.27), 0.104$ & $-0.70(-1.53,0.13), 0.098$ \\
CADF & $-3.33(-5.49,-1.18), 0.002$ & $-1.53(-2.79,-0.26), 0.018$ & $-1.16(-2.49,0.18), 0.091$ & - \\
TRF & - & - & - & $-0.19(-0.02,0.41), 0.082$ \\
VLCD & $-1.82(-2.95,-0.69), 0.002$ & $-0.63(-1.86,0.60), 0.313$ & $-0.23(-1.95,1.49), 0.790$ & 0.00 \\
Subjects & & & $-0.50(-1.27,0.27), 0.200$ & $-0.15(-0.94,0.64), 0.717$ \\
$\quad$ Adult(W+M) & $-2.07(-3.17,-0.96),<0.001$ & $-0.22(-1.01,0.56), 0.579$ & $-1.16(-3.46,1.15), 0.325$ & $-1.05(-1.89,-0.20), 0.015$ \\
$\quad \begin{array}{l}\text { Adult(W) } \\
\text { Adult(M) }\end{array}$ & $-3.33(-5.49,-1.18), 0.002$ & $-1.55(-3.74,0.63), 0.163$ & $-1.87(-2.37,-1.37),<0.001$ & $0.94(-0.96,2.85), 0.331$
\end{tabular}


Table 3 (Contd.)

\begin{tabular}{|c|c|c|c|c|}
\hline \multirow[b]{2}{*}{ Factors } & \multicolumn{4}{|c|}{ Standard mean difference (95\% CI), $P$} \\
\hline & WC & $\mathrm{TC}$ & LDL-C & HDL-C \\
\hline NF & $-2.90(-4.56,-1.24), 0.001$ & $-1.06(-2.09,-0.04), 0.042$ & $-1.38(-2.15,-0.61),<0.001$ & $-0.80(-1.66,0.07), 0.071$ \\
\hline $\mathrm{F}$ & $-1.04(-1.56,-0.52),<0.001$ & $0.47(-0.07,1.00), 0.087$ & $0.50(-0.06,1.06), 0.081$ & $0.85(0.07,1.62), 0.032$ \\
\hline \multicolumn{5}{|l|}{ Fasting time } \\
\hline$<12$ weeks & $-2.59(-4.26,-0.91), 0.002$ & $-1.15(-2.15,-0.16), 0.023$ & $-1.00(-1.99,-0.02), 0.046$ & $0.06(-1.01,1.14), 0.907$ \\
\hline$\geq 12$ weeks & $-2.20(-3.44,-0.95), 0.001$ & $-0.22(-1.18,0.74), 0.654$ & $-0.77(-1.76,0.22), 0.129$ & $-0.23(-1.06,0.60), 0.590$ \\
\hline \multicolumn{5}{|l|}{ Region } \\
\hline Oceania & $-2.85(-4.97,-0.73), 0.008$ & $-0.84(-2.49,0.82), 0.321$ & $-0.72(-1.96,0.51), 0.251$ & $-1.09(-1.45,-0.72),<0.001$ \\
\hline America & - & $-0.15(-1.79,1.49), 0.858$ & $-0.79(-2.09,0.50), 0.228$ & $-0.27(-1.97,1.43), 0.756$ \\
\hline Europe & $-1.25(-1.83,-0.67),<0.001$ & $-0.03(-0.55,0.49), 0.914$ & $-0.79(-2.82,1.23), 0.443$ & $0.71(0.10,1.32), 0.024$ \\
\hline Asia & - & $-2.65(-3.19,-2.11),<0.001$ & - & - \\
\hline \multicolumn{5}{|l|}{ Diabetes } \\
\hline No & $-2.48(-3.71,-1.26),<0.001$ & $-0.98(-1.96,0.01), 0.052$ & $-1.38(-2.15,-0.61),<0.001$ & $-0.55(-1.24,0.15), 0.125$ \\
\hline Yes & $-1.63(-2.51,-0.75),<0.001$ & $0.26(-0.51,1.03), 0.506$ & $0.50(-0.06,1.06), 0.081$ & $1.48(-0.32,3.29), 0.108$ \\
\hline
\end{tabular}

\begin{tabular}{|c|c|c|c|c|c|c|}
\hline \multirow[b]{2}{*}{ Factors } & \multicolumn{6}{|c|}{ Standard mean difference (95\% CI), $P$} \\
\hline & TG & \multicolumn{2}{|l|}{ SBP } & DBP & \multicolumn{2}{|l|}{ BG } \\
\hline \multicolumn{7}{|l|}{ Fasting type } \\
\hline $\mathrm{ADMF}$ & $-0.89(-2.68,0.90), 0.331$ & \multicolumn{2}{|c|}{$-1.48(-3.58,0.62), 0.166$} & $-0.62(-1.49,0.26), 0.168$ & \multicolumn{2}{|c|}{$-1.51(-5.72,2.69), 0.481$} \\
\hline $\mathrm{CADF}$ & $-0.67(-1.83,0.49), 0.255$ & \multicolumn{2}{|c|}{$-1.55(-3.16,0.07), 0.060$} & $-1.11(-2.10,-0.13), 0.026$ & \multicolumn{2}{|c|}{$0.02(-1.97,2.01), 0.986$} \\
\hline TRF & - & \multicolumn{2}{|l|}{ - } & \multirow{2}{*}{$\begin{array}{l}-0.63(-1.26,0.01), 0.054 \\
-\end{array}$} & \multicolumn{2}{|l|}{-} \\
\hline VLCD & $-0.33(-0.69,0.04), 0.079$ & \multicolumn{2}{|c|}{$-0.83(-1.55,-0.10), 0.027$} & & \multicolumn{2}{|c|}{$-0.14(-0.45,0.17), 0.384$} \\
\hline \multicolumn{7}{|l|}{ Subjects } \\
\hline Adult(W + M) & $-0.66(-1.21,-0.12), 0.017$ & \multirow{3}{*}{\multicolumn{2}{|c|}{$\begin{array}{l}-0.82(-1.46,-0.19), 0.011 \\
-1.55(-3.16,0.07), 0.060 \\
-\end{array}$}} & \multirow{3}{*}{$\begin{array}{l}-0.44(-0.84,-0.04), 0.033 \\
-1.11(-2.10,-0.13), 0.026 \\
-\end{array}$} & \multirow{3}{*}{\multicolumn{2}{|c|}{$\begin{array}{l}-0.13(-0.66,0.41), 0.644 \\
-0.59(-3.53,2.35), 0.694 \\
-0.65(-1.07,-0.22), 0.003\end{array}$}} \\
\hline Adult(W) & $-0.07(-0.58,0.44), 0.791$ & & & & & \\
\hline Adult(M) & $-0.93(-2.05,0.20), 0.107$ & & & & & \\
\hline \multicolumn{7}{|l|}{ Outcome type } \\
\hline NF & $-0.86(-1.57,-0.14), 0.019$ & & & $-0.81(-1.42,-0.21), 0.008$ & $-0.49(-$ & $0.35), 0.252$ \\
\hline $\mathrm{F}$ & $-0.24(-0.58,0.11), 0.178$ & $-0.35(-0.98,0.2$ & 280 & $-0.49(-1.20,0.22), 0.174$ & $-0.08(-$ & $0.26), 0.641$ \\
\hline Fasting time & & & & & & \\
\hline$<12$ weeks & $-0.76(-1.51,-0.00), 0.049$ & $-1.50(-2.28,-0$ & 0.001 & $-0.88(-1.38,-0.38), 0.001$ & $0.00(-0$ & $89), 0.995$ \\
\hline$\geq 12$ weeks & $-0.53(-1.05,-0.01), 0.046$ & $-0.87(-1.61,-0$ & 0.021 & $-0.61(-1.18,-0.03), 0.039$ & $-0.49(-$ & $0.11), 0.108$ \\
\hline Region & & & & & & \\
\hline Oceania & $0.22(-0.27,0.71), 0.384$ & $-0.89(-2.40,0.6$ & 245 & $-0.77(-1.56,0.02), 0.056$ & $-0.16(-$ & $1.35), 0.832$ \\
\hline America & $-1.14(-2.28,-0.00), 0.049$ & $-1.85(-3.08,-0$ & 0.003 & $-0.97(-1.88,-0.06), 0.037$ & $-0.72(-$ & $0.69), 0.317$ \\
\hline Europe & $-0.69(-1.22,-0.17), 0.010$ & $-0.10(-0.58,0.3$ & 692 & $-0.11(-0.62,0.40), 0.664$ & $-0.06(-$ & $0.42), 0.793$ \\
\hline Asia & - & $-2.23(-2.74,-1$ & $<0.001$ & $-1.34(-3.13,0.45), 0.141$ & $-0.30(-$ & $0.26), 0.294$ \\
\hline Diabetes & & & & & & \\
\hline No & $-0.65(-1.21,-0.10), 0.021$ & $-1.26(-2.09,-0$ & 0.003 & $-0.71(-1.24,-0.19), 0.007$ & $-0.38(-$ & $0.23), 0.221$ \\
\hline Yes & $-0.53(-1.25,0.20), 0.156$ & $-0.64(-1.18,-0$ & 0.018 & $-0.66(-1.52,0.20), 0.134$ & $-0.02(-$ & $0.68), 0.947$ \\
\hline & Standard mean difference $(\mathrm{s}$ & $\% \mathrm{CI}), P$ & Heterogenei & ity $I^{2}(\%), P$ & & \\
\hline Factors & Insulin & BW & BMI & FEM & FM & WC \\
\hline Fasting type & & & & & & \\
\hline $\mathrm{ADMF}$ & $0.76(-0.76,2.28), 0.329$ & $98.0,<0.001$ & $92.6,<0.001$ & $96.0,<0.001$ & $97.0,<0.001$ & - \\
\hline $\mathrm{CADF}$ & $0.37(-2.27,3.01), 0.784$ & $97.0,<0.001$ & - & $94.2,<0.001$ & $97.3,<0.001$ & $85.9,0.008$ \\
\hline TRF & - & - & - & - & $0.0,0.667$ & - \\
\hline VLCD & $-0.51(-0.75,-0.26),<0.001$ & $93.5,<0.001$ & $83.6,<0.001$ & $88.3,<0.001$ & $98.1,<0.001$ & $96.2,<0.001$ \\
\hline Subjects & & & & & & \\
\hline Adult(W + M) & $0.00(-0.47,0.47), 0.997$ & $95.6,<0.001$ & $90.3,<0.001$ & $94.1,<0.001$ & $97.6,<0.001$ & $96.1,<0.001$ \\
\hline Adult(W) & $-0.13(-4.49,4.23), 0.953$ & $96.4,<0.001$ & - & $88.8,<0.001$ & $86.6,0.006$ & $85.9,<0.001$ \\
\hline Adult(M) & - & $0.0,0.509$ & $0.0,0.595$ & $67.2,0.047$ & $0.0,0.522$ & - \\
\hline Outcome type & & & & & & \\
\hline $\mathrm{NF}$ & $0.02(-1.31,1.35), 0.974$ & $96.1,<0.001$ & $92.9,<0.001$ & - & - & $96.9,<0.001$ \\
\hline $\mathrm{F}$ & $-0.50(-0.73,-0.26),<0.001$ & $90.8,<0.001$ & $68.2,0.024$ & - & - & $60.0,0.082$ \\
\hline Fasting time & & & & & & \\
\hline$<12$ weeks & $-0.39(-2.15,1.37), 0.665$ & $91.4,<0.001$ & $81.9,0.001$ & $92.4,<0.001$ & $94.7,<0.001$ & $88.7,<0.001$ \\
\hline$\geq 12$ weeks & $-0.12(-0.61,0.37), 0.628$ & $96.3,<0.001$ & $91.5,<0.001$ & $92.2,<0.001$ & $97.7,<0.001$ & $96.6,<0.001$ \\
\hline Region & & & & & & \\
\hline Oceania & $-0.07(-2.02,1.88), 0.941$ & $98.5,<0.001$ & $86.9,0.006$ & $91.6,<0.001$ & $98.4,<0.001$ & $97.7,<0.001$ \\
\hline America & $0.50(-0.56,1.55), 0.355$ & $91.2,<0.001$ & $84.0,0.012$ & $95.5,<0.001$ & $85.9,<0.001$ & - \\
\hline Europe & $-0.99(-1.77,-0.20), 0.014$ & $70.4,0.002$ & $66.8,0.017$ & - & - & $69.9,0.019$ \\
\hline Asia & - & $35.5,0.199$ & $0.0,0.778$ & $83.5,0.014$ & - & - \\
\hline
\end{tabular}


Table 3 (Contd.)

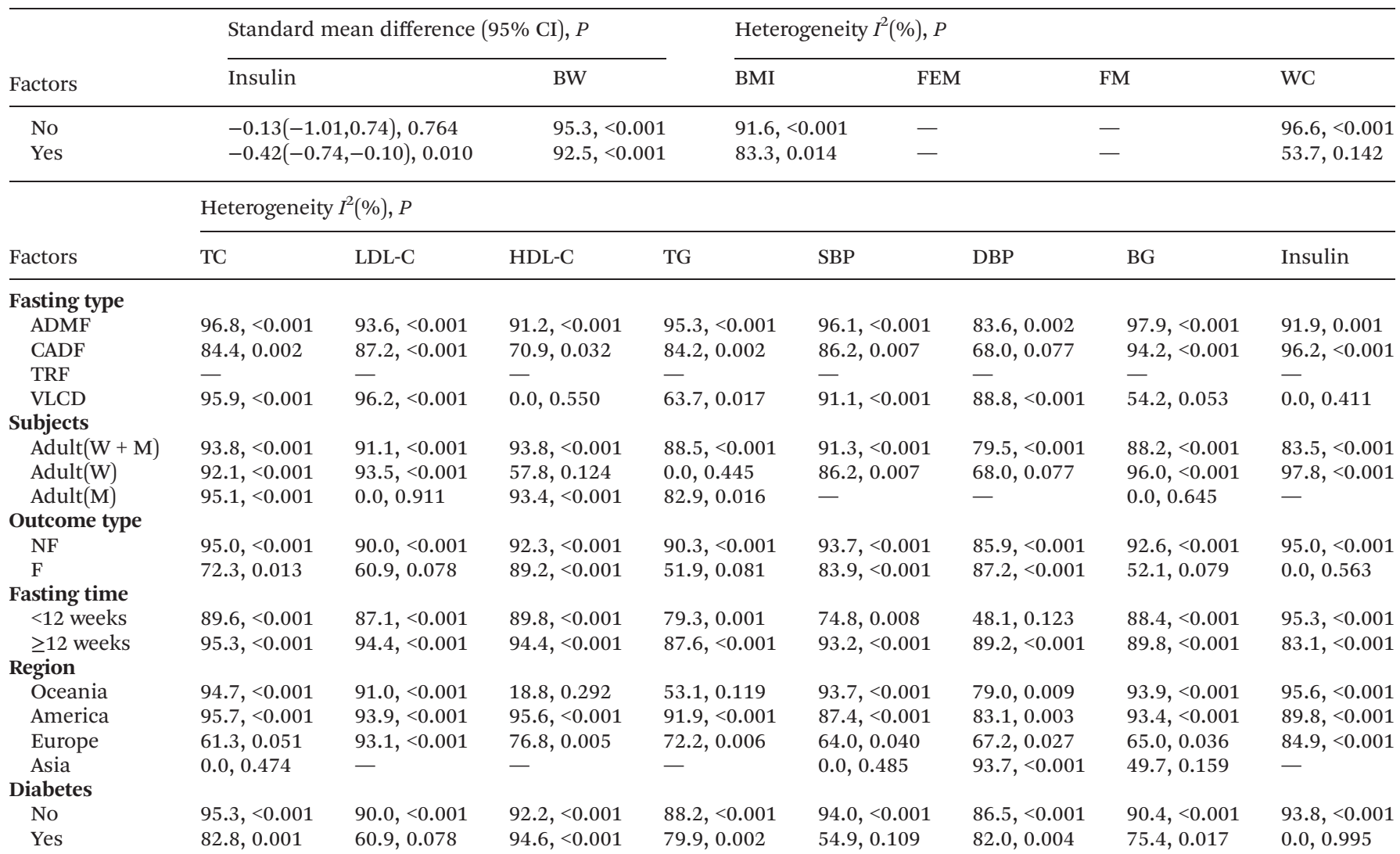

ADMF, alternate day modified fasting; CADF, complete alternate-day fasting; TRF, time-restricted feeding; VLCD, very low calorie diet; Adult(W + M), Adult(women + men); Adult(W), Adult(women); Adult(M), Adult(men); NF, non follow-up; F, follow-up; BW, body weight; BMI, body mass index; FEM, fat free mass; FM, fat mass; WC, waist circumference; TC, total cholesterol; LDL-C, low density lipoprotein cholesterol; HDL-C, high density lipoprotein cholesterol; TG, triglycerides; SBP, systolic blood pressure; DBP, diastolic blood pressure; BG, blood glucose.

Table 4 Publication bias (Egger test) and sensitivity analysis (trim and fill method) performed for included studies

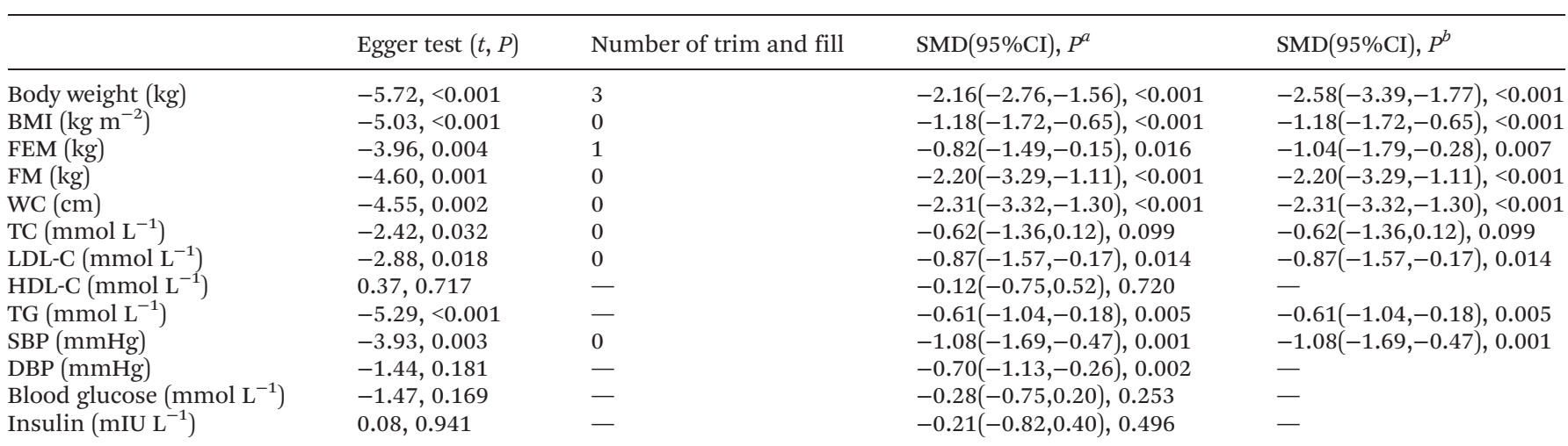

BMI: body mass index; FEM: fat free mass; FM: fat mass; WC: waist circumference; TC: total cholesterol; LDL-C: low density lipoprotein cholesterol; HDL-C: high density lipoprotein cholesterol; TG: triglycerides; SBP: systolic blood pressure; DBP: diastolic blood pressure. ${ }^{a}$ Original variation. ${ }^{b}$ Variation after trim and fill.

\section{Conclusion}

Our study found that fasting intervention had a significant effect on the regulation of anthropometric and metabolic parameters by significantly reducing the body weight, BMI, FEM,
FM, WC, LDL-C, TG, SBP and DBP in people with overweight or obesity. Considering some limitations found in this study, more data from large clinical trials are needed to affirm the efficacy of fasting for the regulation of anthropometric and metabolic parameters in people with overweight or obesity. 


\section{Author contributions}

BL, WC, and SY made the study design; SY, CW, and HZ conducted the study; SY, CW, and YP analyzed the data and wrote the manuscript; SY, HW, YG and NY attended the manuscript revision. All authors agreed with the final manuscript.

\section{Conflicts of interest}

The authors declare that there are no conflicts of interest regarding the publication of this paper.

\section{Acknowledgements}

This work was supported by the National Natural Science Foundation of China (No. 81973129).

\section{References}

1 D. K. Dahiya, Renuka, M. Puniya, U. K. Shandilya, T. Dhewa, et al., Gut Microbiota Modulation and Its Relationship with Obesity Using Prebiotic Fibers and Probiotics: A Review, Front. Microbiol., 2017, 8, 563.

2 A. Afshin, M. H. Forouzanfar, M. B. Reitsma, P. Sur, K. Estep, et al., Health Effects of Overweight and Obesity in 195 Countries over 25 Years, N. Engl. J. Med., 2017, 377, 1327.

3 Y. C. Wang, K. McPherson, T. Marsh, S. L. Gortmaker and M. Brown, Health and economic burden of the projected obesity trends in the USA and the UK, Lancet, 2011, 378, 815-825.

4 K. Rtveladze, T. Marsh, S. Barquera, L. M. Sanchez Romero, D. Levy, et al., Obesity prevalence in Mexico: impact on health and economic burden, Public Health Nutr., 2014, 17, 233-239.

5 L. Keaver, L. Webber, A. Dee, F. Shiely, T. Marsh, et al., Application of the UK foresight obesity model in Ireland: the health and economic consequences of projected obesity trends in Ireland, PLoS One, 2013, 8, e79827.

6 V. D. Longo and M. P. Mattson, Fasting: molecular mechanisms and clinical applications, Cell Metab., 2014, 19, 181192.

7 A. Michalsen and C. Li, Fasting therapy for treating and preventing disease - current state of evidence, Forsch. Komplementarmedi., 2013, 20, 444-453.

8 S. D. Anton, K. Moehl, W. T. Donahoo, K. Marosi, S. A. Lee, et al., Flipping the Metabolic Switch: Understanding and Applying the Health Benefits of Fasting, Obesity, 2018, 26, 254-268.

9 L. Harris, S. Hamilton, L. B. Azevedo, J. Olajide, C. De Brun, et al., Intermittent fasting interventions for treatment of overweight and obesity in adults: a systematic review and meta-analysis, JBI Database Syst. Rev. Implement. Repo., 2018, 16, 507-547.
10 A. R. Barnosky, K. K. Hoddy, T. G. Unterman and K. A. Varady, Intermittent fasting vs daily calorie restriction for type 2 diabetes prevention: a review of human findings, Transl. Res., 2014, 164, 302-311.

11 R. E. Patterson and D. D. Sears, Metabolic Effects of Intermittent Fasting, Annu. Rev. Nutr., 2017, 37, 371.

12 J. Bowen, E. Brindal, G. James-Martin and M. Noakes, Randomized Trial of a High Protein, Partial Meal Replacement Program with or without Alternate Day Fasting: Similar Effects on Weight Loss, Retention Status, Nutritional, Metabolic, and Behavioral Outcomes, Nutrients, 2018, 10, 1145-1160.

13 M. P. Mattson, V. D. Longo and M. Harvie, Impact of intermittent fasting on health and disease processes, Ageing Res. Rev., 2017, 39, 46-58.

14 L. G. Darlington, N. W. Ramsey and J. R. Mansfield, Placebo-controlled, blind study of dietary manipulation therapy in rheumatoid arthritis, Lancet, 1986, 1, 236238.

15 L. Skoldstam, L. Larsson and F. D. Lindstrom, Effect of fasting and lactovegetarian diet on rheumatoid arthritis, Scand. J. Rheumatol., 1979, 8, 249-255.

16 J. Guevara-Aguirre, P. Balasubramanian, M. GuevaraAguirre, M. Wei, F. Madia, et al., Growth hormone receptor deficiency is associated with a major reduction in proaging signaling, cancer, and diabetes in humans, Sci. Transl. Med., 2011, 3, 70ra13.

17 A. Nencioni, I. Caffa, S. Cortellino and V. D. Longo, Fasting and cancer: molecular mechanisms and clinical application, Nat. Rev. Cancer, 2018, 18, 707-719.

18 A. Zubrzycki, K. Cierpka-Kmiec, Z. Kmiec and A. Wronska, The role of low-calorie diets and intermittent fasting in the treatment of obesity and type-2 diabetes, J. Physiol. Pharmacol., 2018, 69, 663-683.

19 L. Sellahewa, C. Khan, S. Lakkunarajah and I. Idris, A Systematic Review of Evidence on the Use of Very Low Calorie Diets in People with Diabetes, Curr. Diabetes Rev., 2017, 13, 35-46.

20 J. F. Trepanowski, C. M. Kroeger, A. Barnosky, M. C. Klempel, S. Bhutani, et al., Effect of Alternate-Day Fasting on Weight Loss, Weight Maintenance, and Cardioprotection Among Metabolically Healthy Obese Adults: A Randomized Clinical Trial, JAMA Intern. Med., 2017, 177, 930-938.

21 J. P. Higgins, D. G. Altman, P. C. Gotzsche, P. Juni, D. Moher, et al., The Cochrane Collaboration's tool for assessing risk of bias in randomised trials, BMJ (Clin. Res. Ed.), 2011, 343, d5928.

22 G. H. Guyatt, A. D. Oxman, G. E. Vist, R. Kunz, Y. FalckYtter, et al., GRADE: an emerging consensus on rating quality of evidence and strength of recommendations, $B M J$ (Clin. Res. Ed.), 2008, 336, 924-926.

23 M. Tarsilla, Cochrane Handbook for Systematic Reviews of Interventions, J. Multidiscip. Eval., 2008, 6, 142-148.

24 K. A. Varady, S. Bhutani, M. C. Klempel, C. M. Kroeger, J. F. Trepanowski, et al., Alternate day fasting for weight 
loss in normal weight and overweight subjects: a randomized controlled trial, Nutr. J., 2013, 12, 146.

25 S. Bhutani, M. C. Klempel, C. M. Kroeger, J. F. Trepanowski and K. A. Varady, Alternate day fasting and endurance exercise combine to reduce body weight and favorably alter plasma lipids in obese humans, Obesity, 2013, 21, 13701379.

26 V. A. Catenacci, Z. Pan, D. Ostendorf, S. Brannon, W. S. Gozansky, et al., A randomized pilot study comparing zero-calorie alternate-day fasting to daily caloric restriction in adults with obesity, Obesity, 2016, 24, 1874-1883.

27 A. T. Hutchison, B. Liu, R. E. Wood, A. D. Vincent, C. H. Thompson, et al., Effects of Intermittent Versus Continuous Energy Intakes on Insulin Sensitivity and Metabolic Risk in Women with Overweight, Obesity, 2019, 27, 50-58.

28 T. Moro, G. Tinsley, A. Bianco, G. Marcolin, Q. F. Pacelli, et al., Effects of eight weeks of time-restricted feeding (16/ 8) on basal metabolism, maximal strength, body composition, inflammation, and cardiovascular risk factors in resistance-trained males, J. Transl. Med., 2016, 14, 290.

29 G. M. Tinsley, J. S. Forsse, N. K. Butler, A. Paoli, A. A. Bane, et al., Time-restricted feeding in young men performing resistance training: A randomized controlled trial, Eur. J. Sport Sci., 2017, 17, 200-207.

30 C. Li, B. Sadraie, N. Steckhan, C. Kessler, R. Stange, et al., Effects of A One-week Fasting Therapy in Patients with Type-2 Diabetes Mellitus and Metabolic Syndrome - A Randomized Controlled Explorative Study, Exp. Clin. Endocrinol. Diabetes, 2017, 125, 618-624.

31 C. J. Haywood, L. A. Prendergast, K. Purcell, L. Le Fevre, W. K. Lim, et al., Very Low Calorie Diets for Weight Loss in Obese Older Adults-A Randomized Trial, J. Gerontol., Ser. A, 2017, 73, 59-65.

32 N. M. Hussin, S. Shahar, N. I. Teng, W. Z. Ngah and S. K. Das, Efficacy of fasting and calorie restriction (FCR) on mood and depression among ageing men, J. Nutr., Health Aging, 2013, 17, 674-680.

33 K. M. Burnand, R. P. Lahiri, N. Burr, L. Jansen van Rensburg and M. P. Lewis, A randomised, single blinded trial, assessing the effect of a two week preoperative very low calorie diet on laparoscopic cholecystectomy in obese patients, $H P B, 2016,18,456-461$.

34 N. I. Teng, S. Shahar, Z. A. Manaf, S. K. Das, C. S. Taha, et al., Efficacy of fasting calorie restriction on quality of life among aging men, Physiol. Behav., 2011, 104, 1059-1064.

35 K. Arai, J. Miura, M. Ohno, J. Yokoyama and Y. Ikeda, Comparison of clinical usefulness of very-low-calorie diet and supplemental low-calorie diet, Am. J. Clin. Nutr., 1992, 56, 275s-276s.

36 N. I. Teng, S. Shahar, N. F. Rajab, Z. A. Manaf, M. H. Johari, et al., Improvement of metabolic parameters in healthy older adult men following a fasting calorie restriction intervention, Aging male, 2013, 16, 177-183.

37 R. B. Paisey, P. Harvey, S. Rice, I. Belka and I. Ash, Shortterm results of an open trial of very low calorie diet or intensive conventional diet in Type 2 diabetes, Practical Diabetes Int., 2011, 12, 263-267.

38 R. R. Wing, E. Blair, M. Marcus, L. H. Epstein and J. Harvey, Year-long weight loss treatment for obese patients with type II diabetes: does including an intermittent very-low-calorie diet improve outcome?, Am. J. Med., 1994, 97, 354-362.

39 J. S. Torgerson, L. Lissner, A. K. Lindroos, H. Kruijer and L. Sjostrom, VLCD plus dietary and behavioural support versus support alone in the treatment of severe obesity. A randomised two-year clinical trial, Int. J. Obes. Relat. Metab. Disord., 1997, 21, 987-994.

40 T. A. Wadden, G. D. Foster and K. A. Letizia, One-year behavioral treatment of obesity: comparison of moderate and severe caloric restriction and the effects of weight maintenance therapy, J. Consult. Clini. Psychol., 1994, 62, 165-171.

41 K. Purcell, P. Sumithran, L. A. Prendergast, C. J. Bouniu, E. Delbridge, et al., The effect of rate of weight loss on long-term weight management: a randomised controlled trial, Lancet Diabetes Endocrinol., 2014, 2, 954-962.

42 B. Stenius-Aarniala, T. Poussa, J. Kvarnstrom, E. L. Gronlund, M. Ylikahri, et al., Immediate and long term effects of weight reduction in obese people with asthma: randomised controlled study, BMJ (Clin. Res. Ed.), 2000, 320, 827-832.

43 T. A. Wadden and A. J. Stunkard, Controlled trial of very low calorie diet, behavior therapy, and their combination in the treatment of obesity, J. Consult. Clin. Psychol., 1986, 54, 482-488.

44 H. Tuomilehto, H. Gylling, M. Peltonen, T. Martikainen, J. Sahlman, et al., Sustained improvement in mild obstructive sleep apnea after a diet- and physical activity-based lifestyle intervention: postinterventional follow-up, Am. J. Clin. Nutr., 2010, 92, 688-696.

45 H. P. Tuomilehto, J. M. Seppa, M. M. Partinen, M. Peltonen, $\mathrm{H}$. Gylling, et al., Lifestyle intervention with weight reduction: first-line treatment in mild obstructive sleep apnea, Am. J. Respir. Crit. Care Med., 2009, 179, 320-327.

46 T. A. Wadden, A. J. Stunkard and J. Liebschutz, Three-year follow-up of the treatment of obesity by very low calorie diet, behavior therapy, and their combination, J. Consult. Clin. Psychol., 1988, 56, 925-928.

47 K. V. Williams, M. L. Mullen, D. E. Kelley and R. R. Wing, The effect of short periods of caloric restriction on weight loss and glycemic control in type 2 diabetes, Diabetes Care, 1998, 21, 2-8.

48 F. G. Cahill, Fuel Metabolism in Starvation, Annu. Rev. Nutr., 2006, 26, 1-22.

49 A. Di Francesco, C. Di Germanio, M. Bernier and R. de Cabo, A time to fast, Science, 2018, 362, 770-775.

50 L. B. Gano, M. Patel and J. M. Rho, Ketogenic diets, mitochondria, and neurological diseases, J. Lipid Res., 2014, 55, 2211-2228.

51 G. F. Cahill Jr., Fuel metabolism in starvation, Annu. Rev. Nutr., 2006, 26, 1-22. 
52 A. C. St-Pierre, I. L. Ruel, B. Cantin, G. R. Dagenais, P. M. Bernard, et al., Comparison of various electrophoretic characteristics of LDL particles and their relationship to the risk of ischemic heart disease, Circulation, 2001, 104, 2295-2299.

53 B. G. Nordestgaard, M. Benn, P. Schnohr and A. TybjaergHansen, Nonfasting triglycerides and risk of myocardial infarction, ischemic heart disease, and death in men and women, J. Am. Med. Assoc., 2007, 298, 299-308.

54 K. A. Varady, S. Bhutani, M. C. Klempel and B. Lamarche, Improvements in LDL particle size and distribution by short-term alternate day modified fasting in obese adults, Br. J. Nutr., 2011, 105, 580-583.

55 I. Cioffi, A. Evangelista, V. Ponzo, G. Ciccone, L. Soldati, et al., Intermittent versus continuous energy restriction on weight loss and cardiometabolic outcomes: a systematic review and meta-analysis of randomized controlled trials, J. Transl. Med., 2018, 16, 15.

56 B. D. Horne, J. B. Muhlestein and J. L. Anderson, Health effects of intermittent fasting: hormesis or harm? A systematic review, Am. J. Clin. Nutr., 2015, 102, 464-470.

57 V. D. Longo and M. P. Mattson, Fasting: Molecular Mechanisms and Clinical Applications, Cell Metab., 2014, 19, 181-192.

58 S. Golbidi, A. Daiber, B. Korac, H. Li, M. F. Essop, et al., Health Benefits of Fasting and Caloric Restriction, Curr. Diabetes Rep., 2017, 17, 11.

59 K. H. Kim, Y. H. Kim, J. E. Son, J. H. Lee, S. Kim, et al., Intermittent fasting promotes adipose thermogenesis and metabolic homeostasis via VEGF-mediated alternative activation of macrophage, Cell Res., 2017, 27, 1309-1326.

60 R. V. Seimon, J. A. Roekenes, J. Zibellini, B. Zhu, A. A. Gibson, et al., Do intermittent diets provide physio- logical benefits over continuous diets for weight loss? A systematic review of clinical trials, Mol. Cell. Endocrinol., 2015, 418(Pt 2), 153-172.

61 G. M. Tinsley and P. M. La Bounty, Effects of intermittent fasting on body composition and clinical health markers in humans, Nutr. Rev., 2015, 73, 661674.

62 S. E. Shoelson, L. Herrero and A. Naaz, Obesity, Inflammation, and Insulin Resistance, Gastroenterology, 2007, 132, 2169-2180.

63 A. Brown, N. Guess, A. Dornhorst, S. Taheri and G. Frost, Insulin-associated weight gain in obese type 2 diabetes mellitus patients: What can be done?, Diabetes, Obes. Metab., 2017, 19, 1655-1668.

64 E. L. Lim, K. G. Hollingsworth, B. S. Aribisala, M. J. Chen, J. C. Mathers, et al., Reversal of type 2 diabetes: normalisation of beta cell function in association with decreased pancreas and liver triacylglycerol, Diabetologia, 2011, 54, 2506-2514.

65 R. R. Wolfe, Effects of insulin on muscle tissue, Curr. Opin. Clin. Nutr. Metab. Care, 2000, 3, 67-71.

66 A. R. Saltiel and C. R. Kahn, Insulin signalling and the regulation of glucose and lipid metabolism, Nature, 2001, 414, 799-806.

67 R. M. Anson, Z. Guo, R. de Cabo, T. Iyun, M. Rios, et al., Intermittent fasting dissociates beneficial effects of dietary restriction on glucose metabolism and neuronal resistance to injury from calorie intake, Proc. Natl. Acad. Sci. U. S. A., 2003, 100, 6216-6220.

68 S. Yan, Z. Tian, M. Li, B. Li and W. Cui, Effects of probiotic supplementation on the regulation of blood lipid levels in overweight or obese subjects: a meta-analysis, Food Funct., 2019, 10, 1747-1759. 